\title{
BMJ Global Health Impact of COVID-19 pandemic lockdown on movement behaviours of children and adolescents: a systematic review
}

\author{
Madhu Kharel (D) , ${ }^{1}$ Jennifer Lisa Sakamoto (D) , ${ }^{1}$ Rogie Royce Carandang (D) , \\ Shinejil Ulambayar, ${ }^{1}$ Akira Shibanuma (D) , ${ }^{1}$ Ekaterina Yarotskaya, ${ }^{2}$ \\ Milana Basargina, ${ }^{3}$ Masamine Jimba ${ }^{1}$
}

To cite: Kharel M, Sakamoto JL, Carandang RR, et al. Impact of COVID-19 pandemic lockdown on movement behaviours of children and adolescents: a systematic review. BMJ Global Health 2022;7:e007190. doi:10.1136/ bmjgh-2021-007190

Handling editor Seye Abimbola

- Additional supplemental material is published online only. To view, please visit the journal online (http://dx.doi.org/10. 1136/bmjgh-2021-007190)

Received 16 August 2021 Accepted 3 January 2022
Check for updates

C Author(s) (or their employer(s)) 2022. Re-use permitted under CC BY-NC. No commercial re-use. See rights and permissions. Published by BMJ

For numbered affiliations see end of article.

Correspondence to Jennifer Lisa Sakamoto; jlsakamoto@m.u-tokyo.ac.jp

\section{ABSTRACT}

Introduction Several studies have examined how the lockdown restrictions enforced to halt the spread of COVID-19 have affected children and adolescents' movement behaviours, but there is a need to synthesise these findings. Therefore, we conducted this systematic review to examine the impact of COVID-19 lockdown on children and adolescents' movement behaviours.

Methods We searched eight databases and grey literature for relevant studies of all study designs; and conducted a narrative analysis of the results following synthesis without meta-analysis guidelines. We used appropriate tools to assess the risk of bias in quantitative and qualitative studies. We compared changes in physical activity, screen time and sleep duration and quality from before to during the COVID-19 lockdown.

Results This review included 71 studies reporting data from 35 countries and territories, mostly from high-income economies. A majority of the studies used a cross-sectiona design and had fair to poor-quality ratings. Most studies reported reduced physical activity, increased screen time and longer sleep hours among children and adolescents. Children and adolescents facing strict lockdowns saw a larger decline in physical activity and a sharper increase in screen time than those under mild restrictions.

Conclusion COVID-19-related lockdowns were detrimental to children and adolescents' movement behaviours, with stricter lockdowns tending to have a bigger impact. Children and adolescents under COVID-19 restrictions are likely to be less active, spend more time on screen, and sleep longer hours than before the lockdown. More studies from low-income and middle-income countries could provide a clearer picture of the impact. PROSPERO registration number CRD42021245924.

\section{INTRODUCTION}

COVID-19, one of the biggest pandemics in the history of humankind, has affected almost every country worldwide. The COVID-19 outbreak that started in Wuhan, China, in December 2019 has caused 317.26 million infections and 5.52 million deaths globally as

\section{Key questions}

What is already known?

- Lockdown restrictions to curb the spread of COVID-19 may have affected movement behaviours of children and adolescents.

What are the new findings?

- Lockdown measures to contain the spread of COVID-19 had mostly negative consequences on the movement behaviours of children and adolescents worldwide, with children spending less time on physical activity and more time on screens during confinement than before the pandemic

- Children and adolescents facing milder restrictions, such that they were allowed to go outdoors for exercise while maintaining social distance, were physically more active and used screens less than those under stricter lockdowns.

- Children and adolescents had later bedtime and wake-up time during the pandemic than before the pandemic.

\section{What do the new findings imply?}

-When implementing measures to contain the spread of infections, authorities should carefully consider the negative consequences of the measures on the healthy movement behaviours of children and adolescents.

- Such measures should be introduced in a way that would have the least effect on children and adolescents' healthy movement behaviours.

of 13 January 2022. ${ }^{1}$ WHO declared a Public Health Emergency of International Concern on 30 January 2020 to accelerate action against the rapidly spreading coronavirus. ${ }^{2}$ Following the WHO recommendations, governments in many countries started to enforce lockdown measures to curb the spread of the virus. During these lockdowns, schools, businesses and other non-essential services were closed, and people were advised to stay inside their 
homes. In extreme cases, public parks were also closed, and people were not allowed to go out, except for emergencies. ${ }^{3}$

Lockdown restrictions greatly affected people's lives, especially those of children and adolescents. ${ }^{4}$ Schools, where children and adolescents spend a significant amount of time, were closed for months. Their daily routines changed drastically, and they had more free time. However, as they had limited opportunity to go outdoors due to lockdown restrictions and fear of contracting the virus while being outdoors, ${ }^{5}$ they had to spend most of their time inside their residence. Such confinement of children and adolescents inside their house during this active age can negatively affect their movement behaviours-physical activity, sedentary behaviour and sleep. ${ }^{6}$

Healthy movement behaviours-adequate physical activity, limited sedentary behaviour, and sufficient sleep-are critical for healthy childhood development. ${ }^{7}$ However, these behaviours might be compromised during lockdown restrictions. School closure means children cannot participate in physical education classes, which are a significant contributor to children's total physical activity under normal circumstances. ${ }^{8}$ School closure also affects active commute to and from the school. ${ }^{9}$ Additionally, having limited opportunities to go outdoors during the lockdown would significantly reduce children's outdoor play. Confined children with more free time might turn to screen-based electronic devices such as mobile phones, tablets, computers and television for leisure activities. ${ }^{10}$ Children's sleep patterns might become irregular as they do not have to attend regular classes. $^{11}{ }^{12}$ Their sleep quality might decrease during the lockdown because of the fear and anxiety caused by the pandemic. ${ }^{13-15}$ Unhealthy movement behaviours are associated with adverse health outcomes such as obesity, hypertension, diabetes, cardiovascular diseases, poor mental health and lower health-related quality of life. ${ }^{16-18}$

Several individual studies have been conducted in various countries to see the impact of COVID-19-related lockdown restrictions on children and adolescents' movement behaviours. However, the results reported by these studies vary in both the degree and the direction of effect. ${ }^{31920}$ Moreover, the degree of lockdown restrictions varies between and within countries and can affect children and adolescents' movement behaviours differently. Stockwell and colleagues conducted a systematic review to examine changes in physical activity and sedentary behaviour from before to during COVID-19 lockdown among the general population. ${ }^{21}$ However, this review included few studies on children and adolescents as it included studies until October 2020. A systematic review and meta-analysis was conducted to assess the prevalence and pattern of sleep disturbances in children and adolescents during the COVID-19 pandemic. However, this review searched articles only in three databases, and therefore, included few studies. ${ }^{22}$ A narrative review of the literature was done to understand health-related behaviours among isolated preschool and school-aged children aged $3-12 .{ }^{23}$ This narrative review included articles from a limited number of databases, focused on children in social isolation and social deprivation, and excluded children with previous health conditions or diseases. Similarly, Paterson et al conducted a scoping review to explore the impact of COVID-19 on the movement behaviours of children and youth aged 5-17 years. However, this review did not appraise the quality of the evidence, included some articles without peer review, and did not account for the varying degrees of lockdown restrictions. ${ }^{24}$ Moreover, many studies have been published on this topic since these reviews were undertaken. Therefore, we conducted this systematic review to comprehensively review the findings from studies conducted in different settings and varying degrees of lockdown restrictions to inform policy decisions on enforcement of lockdowns for subsequent waves of COVID-19 and future pandemics of similar nature.

\section{METHODS}

We registered the review protocol in PROSPERO (registration number: CRD42021245924, see online supplemental file 1) and followed the Preferred Reporting Items for Systematic Reviews and Meta-Analyses (PRISMA) 2020 guidelines and synthesis without meta-analysis (SWiM) guidelines. $^{25}$

\section{Inclusion criteria}

We defined the population, exposure, comparators, outcomes and studies for this review as follows:

Population: Children and adolescents (aged 19 years and below)

Exposure: COVID-19 pandemic lockdown

We took the reference of an earlier study ${ }^{26}$ and used the information provided in each article to categorise the severity of lockdown into the following five categories.

1. Mild lockdown: schools open, advised to maintain social distance.

2. Moderate lockdown: schools closed or available to children of essential workers, advised to stay indoors and maintain social distance while being outdoors.

3. Strict lockdown: schools closed, non-essential businesses closed, mandatory home confinement except for essential reasons, ban on public gatherings, closure of organised sports and recreation facilities, public parks open, allowed to go outdoors at least for a certain time.

4. Very strict lockdown: schools closed, non-essential businesses closed, closure of organised sports and recreation facilities, closure of public parks, not allowed to go outdoors even for exercise.

5. Unclear: no sufficient information on lockdown available.

Comparators: Outcomes before the COVID-19 lockdown versus outcomes during the COVID-19 lockdown. 
Outcomes: Movement behaviours-physical activity, sedentary behaviours and sleep. ${ }^{27}$

To be more specific, physical activity is defined as any bodily movement produced by skeletal muscles that requires energy expenditure. ${ }^{28}$ It can take different forms such as walking, cycling, sports, active recreation and play, and household chores. ${ }^{28}{ }^{29}$ Based on intensity, physical activity can be categorised into light, moderate and vigorous. ${ }^{30}$

Sedentary behaviour is any waking behaviour characterised by an energy expenditure $\leq 1.5$ metabolic equivalents, while in sitting, reclining or lying posture. ${ }^{31}$ Sedentary behaviours include sitting and using screens, such as watching television and using smartphones and computers for playing videogames and accessing the internet and social media. ${ }^{31}$ In this review, sedentary behaviour included use of screens.

Sleep duration is the period between bedtime and wake-up time. ${ }^{32}$ Sleep quality refers to how well one sleeps, and can be determined by various components, such as sleep duration, sleep disturbance, sleep latency and sleep efficiency. ${ }^{33} 34$

Types of studies: We included original research articles with all types of study designs, such as randomised controlled trial (RCT), quasi-experimental, cohort, observational, cross-sectional and other comparative studies, as well as case studies and evaluation reports. We excluded letters, editorials, reviews, conference abstracts and books.

\section{Search strategy}

We searched eight electronic databases: PubMed/ MEDLINE, Web of Science, Cumulative Index of Nursing and Allied Health Literature (CINAHL), PsycINFO, PsycARTICLES, Academic Search Complete, SocINDEX, and Cochrane Central Register of Controlled Trials (CENTRAL); and grey literature: World Health Organization (WHO), Centers for Disease Control and Prevention (CDC), European Centre for Disease Prevention and Control (ECDC), Japan International Cooperation Agency (JICA) and United Nations Children's Fund (UNICEF). Additional studies were hand-searched from the reference lists of included articles. We conducted the search at three time points, initially on 30 March 2021, the first update on 24 September 2021 and the final update on 10 December 2021. We included all published papers in the English language from 1 November 2019 to 10 December 2021.

Our search strategy combined both Medical Subject Headings $(\mathrm{MeSH})$ terms and free-text terms related to children/adolescents AND lockdown AND movement and play behaviours (see online supplemental file 2).

\section{Data extraction}

Authors RRC and JLS independently searched the aforementioned electronic databases using the search strategy outlined in the review protocol. The titles and abstracts of all the articles retrieved from the search were screened by the two researchers independently, and duplicates were removed. The full texts of the potential articles to be included in the study were then reviewed by two researchers (MK and $\mathrm{SU}$ ) independently based on the inclusion criteria. Any discrepancies between the two researchers were resolved through discussion with a third researcher (RRC).

We extracted data from the selected studies using an excel sheet, and included the following information: author, year and country; study title; source; study design; study setting; study population; sample size; mean age; proportion of female; measurement tools for physical activity, sedentary behaviour and sleep; description of lockdown; comparison; outcomes and remarks.

\section{Risk of bias and quality of evidence}

All the studies finally included in this review were observational. We used the 'Quality Assessment Tool for Observational Cohort and Cross-Sectional Studies' of the US Department of Health and Human Services, National Institutes of Health to assess the risk of bias for cohort and cross-sectional studies. ${ }^{35}$ For qualitative studies, we used the 'Qualitative study: Critical Appraisal Skills Programme'. ${ }^{36}$ None of the included studies used RCTs or mixed-methods design. We used an approach reported by Geere $e t$ al to rate the strength of evidence from observational cohort and cross-sectional studies, considering study quality, number of evidence and consistency of findings. ${ }^{37}$

\section{Analysis strategy}

We did not perform a meta-analysis due to the heterogeneity of designs and measures in the included studies. Therefore, we conducted a narrative analysis of the results following the SWiM guidelines (see online supplemental file 3$){ }^{38}$ We categorised studies according to the three outcomes-physical activity, sedentary behaviour (screen time) and sleep (duration and quality), and described changes in relevant indicators from before to during the COVID-19 lockdown (see figure 1). Studies under each outcome were presented based on the direction (ie, increased, decreased, no significant change from before to during the lockdown) and the effect size of their results. When necessary, we standardised the unit of outcome measurements reported among included studies to compare the results easily.

\section{RESULTS}

Figure 2 shows the PRISMA flow diagram. Initially, we retrieved 14241 records from the database search and identified an additional 16 articles from other sources. After removing the duplicates and screening the titles and abstracts of the articles, the full texts of 150 potential articles were assessed. Finally, we included 71 articles after removing ineligible articles (see online supplemental table 1).

Studies included in this review came from a range of countries and territories-11 studies reported data from 


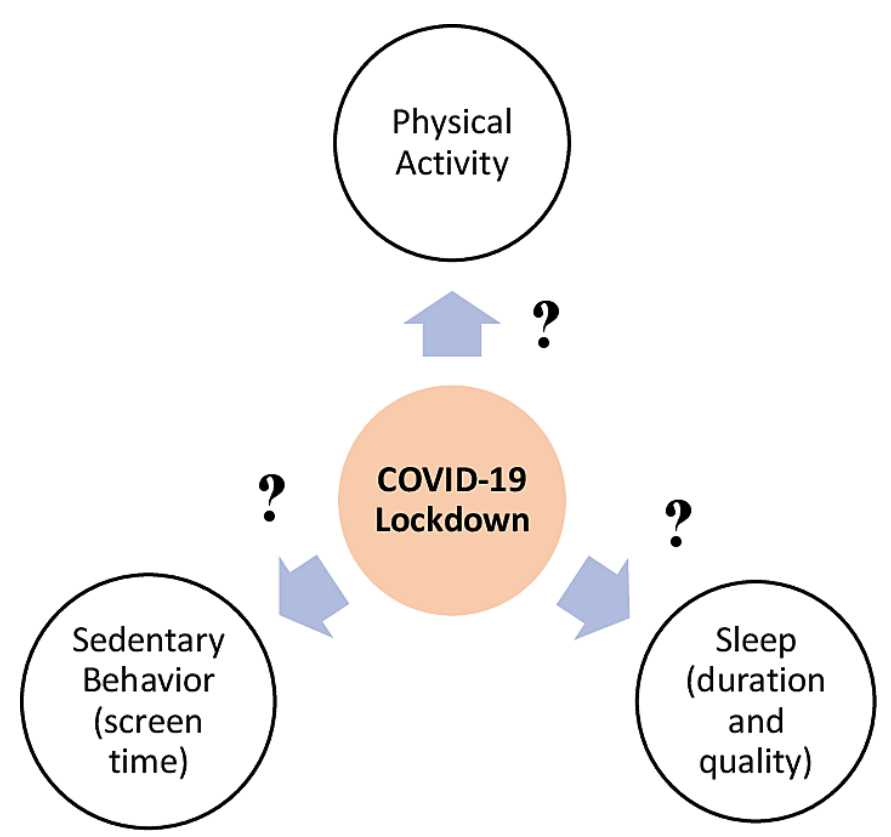

Figure 1 Conceptual framework for the impact of COVID-19 pandemic lockdown on movement and play behaviours of children and adolescents*. *Adapted and modified from WHO's guideline on physical activity, sedentary behaviour and sleep for children under 5 years of age. $^{7}$

Italy; 9 from the USA; 7 each from Spain and Turkey; 6 from Australia; 5 each from Canada and China; 4 each from the UK, Poland and India; 3 each from France and Portugal; 2 each from Germany, the Netherlands, Switzerland, Brazil, Chile, Hong Kong (China) and Malaysia; and 1 each from Croatia, Ireland, Russia, Sweden, Ukraine, Bangladesh, Indonesia, Israel, Pakistan, Singapore, Sri Lanka, Uzbekistan, Vietnam, Colombia, Egypt and Morocco. Of the 71 studies included in this review, 67 were single-country studies-the majority (51) from high-income economies, 13 from upper-middle-income economies and 3 from lower-middle-income economies; and 4 were multicountry studies reporting data from high-income, upper-middle-income and lower-middleincome economies. However, one of the multicountry studies did not specify the countries, instead reported that data were collected mostly from North America, the Middle East, Europe and South America. There were no studies from low-income countries. Twenty-three and 48 studies were published in 2020 and 2021, respectively.

Characteristics of studies included in this review are presented in table 1 . All the studies were observational, and the majority were quantitative studies. Of the 71 studies, 20 were cohort (data were collected at two time points, for before lockdown and during the lockdown; prospective $=18$ and retrospective=2), 48 were cross-sectional (data were collected at the same time, for during lockdown and retrospectively for before the lockdown or repeated cross-sectional), and 3 were qualitative in design. The sample size (range: 9-29 202) and participants' age (range: 1-19 years) among the included studies varied widely. A majority of the studies $(69 \%$, reported strict lockdown, while $9.8 \%$ reported moderate lockdown, $8.5 \%$ reported very strict lockdown, $4.2 \%$ reported mild lockdown and $8.5 \%$ did not provide sufficient information on lockdown.

The risk of bias assessment for the included quantitative studies is presented in online supplemental table 2. Almost all the studies clearly stated their research objective, defined their study population and recruited the study population following the inclusion and exclusion criteria. However, most studies $(86.8 \%)$ did not justify the sample size as they used a convenience sampling strategy. None of the studies measured exposure prior to the outcome because most of them used a cross-sectional study design. More than $86 \%$ of the studies did not have significant issues in measuring exposure and outcome. Only $36.8 \%$ of the studies had adjusted for potential confounders. The quality appraisal of qualitative studies is presented in online supplemental table 3 . All the three studies did not have any major issues in their design and implementation.

\section{Movement behaviours among apparently healthy children and adolescents}

Physical activity

Changes in physical activity from before to during the lockdown are presented in table 2. Thirty-four studies (11 cohort, 21 cross-sectional and 2 qualitative) reported changes in physical activity among apparently healthy children and adolescents from before to during the lockdown. Of these, 25 studies ( 8 cohort and 16 crosssectional and 1 qualitative $)^{32739-61}$ observed a decline in physical activity, 8 ( 2 cohort, 5 cross-sectional and 1 qualitative) ${ }^{9202662-66}$ observed no change and 1 (cohort) ${ }^{19}$ reported an increase in physical activity.

The decline in physical activity among children and adolescents during the lockdown ranged from 102.5 min per week in a study in Spain $^{3}$ to 91 min per day in another study from the same country. ${ }^{52}$ In Brazil, $83 \%$ of the adolescents spent less or much less time on physical activity during the pandemic than before the pandemic, ${ }^{58}$ and the proportion of physically active children reduced from $59.1 \%$ to $7.0 \%$ during the same period. ${ }^{57}$ Reductions in physical activity levels were also observed among children and adolescents in Chile, Singapore, the UK, Croatia, Australia (New South Wales), Canada, Poland, the USA, China, France, Portugal, Italy and Turkey. 2739 41-51 $53555659-61$

In contrast, in some countries, children and adolescents could maintain or even increase their physical activity levels despite the pandemic restrictions. For example, studies from Italy, China, Australia (Western Australia) and Poland observed no significant change in physical activity levels from before to during the lockdown among children and adolescents. ${ }^{20636566}$ A multicountry longitudinal study also reported no significant change in time spent on total physical activity among children aged 3-5 years old. ${ }^{26}$ German children and adolescents were found 


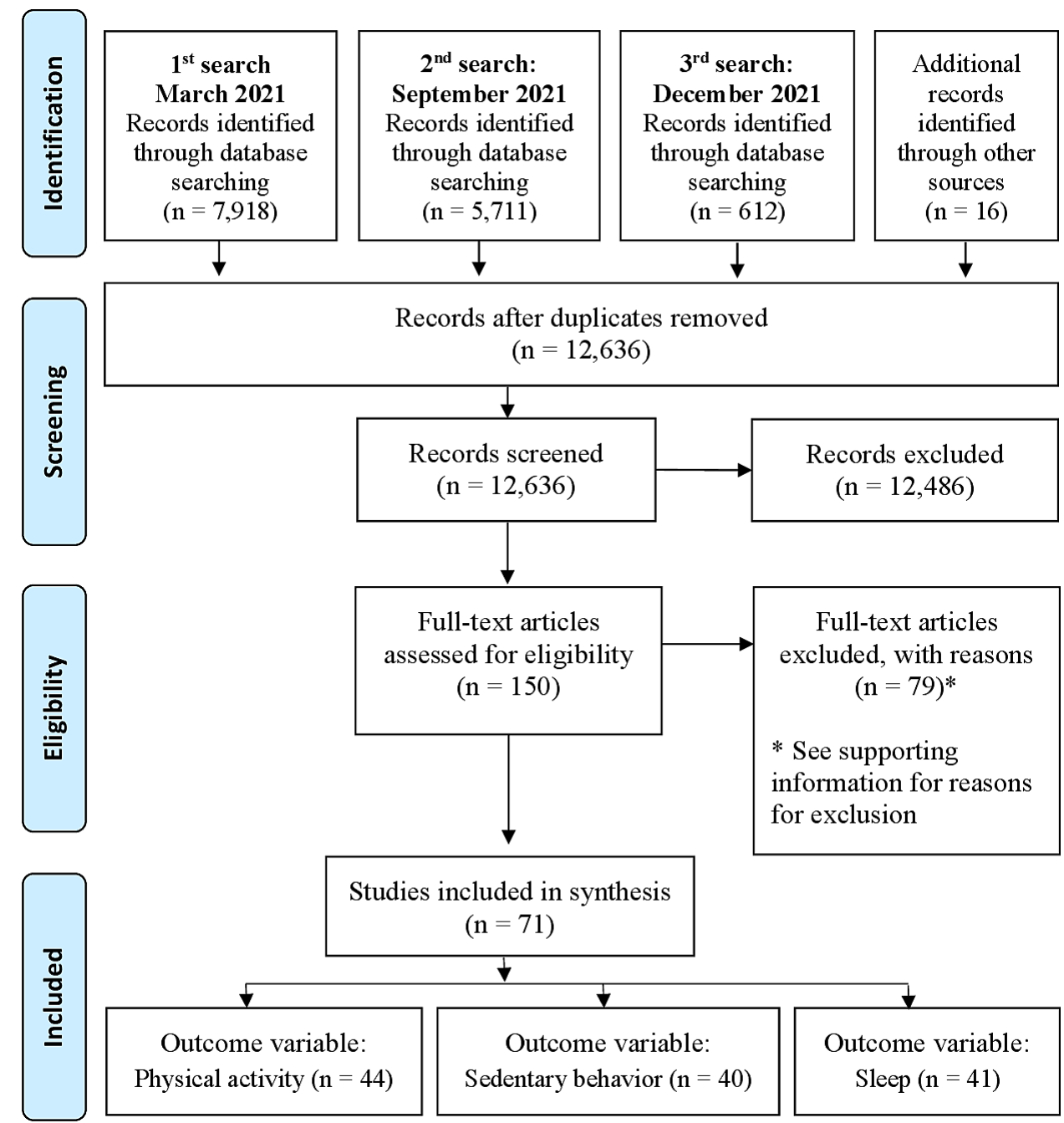

Figure 2 PRISMA flow diagram. PRISMA, Preferred Reporting Items for Systematic Reviews and Meta-Analyses.

to be more active during the COVID-19 lockdown, as the number of days active in a week and the proportion adhering to physical activity guidelines increased during this period (4.3 days/week to 4.7 days/week, $\mathrm{p}<0.01$; and $19.1 \%$ to $30.2 \%, \mathrm{p}<0.01$; respectively). ${ }^{19}$

\section{Sedentary behaviour} Exposure to screen

Changes in screen time from before to during the lockdown are presented in table 3 . Thirty-one studies ( 8 cohort, 21 cross-sectional and 2 qualitative) compared children and adolescents' screen time before and during the lockdown. All of them observed an increase in screen time during the pandemic compared with before the pandemic. During the lockdown, the increase in children's screen time ranged from 55 min per day in a multicountry study ${ }^{26}$ to 2.9 hours per day in Spain. ${ }^{3}$ Another study from Spain found that children's screen time increased by 1.8 hours per day, reaching an alarming figure of 6.1 hours per day during the lockdown. ${ }^{52}$ Singaporean and German children spent daily 1.54 hours and 1.02 hours more, respectively, on screen during the pandemic than before the pandemic. ${ }^{1950}$ In Italy, 9 out of
10 Italian children spent more time on screen during the lockdown than before the lockdown ${ }^{44}$ and the proportion of children and adolescents using smartphone for four or more hours per day increased from $16.3 \%$ before the lockdown to $66.3 \%$ during the lockdown. ${ }^{67}$ In Brazil, nearly three-fourths of the children reported spending more or much more time on screen during the lockdown than before the pandemic. ${ }^{58}$ Similar findings were reported in studies from Canada, China, Turkey and Portugal. ${ }^{49} 535668$ Approximately two-thirds of the children and adolescents in France and India spent more time on screen during the lockdown than before the lockdown. ${ }^{4669}$

\section{Sleep}

Sleep duration, bedtime and wake-up time

Changes in sleep duration, bedtime and wake-up time from before to during the lockdown are presented in table 4 . Twenty-five studies (9 cohort and 16 crosssectional) reported changes in sleep duration among children and adolescents from before to during the pandemic. Twelve studies (five cohort and seven crosssectional) $2739435052616670-74$ reported an increase, two 


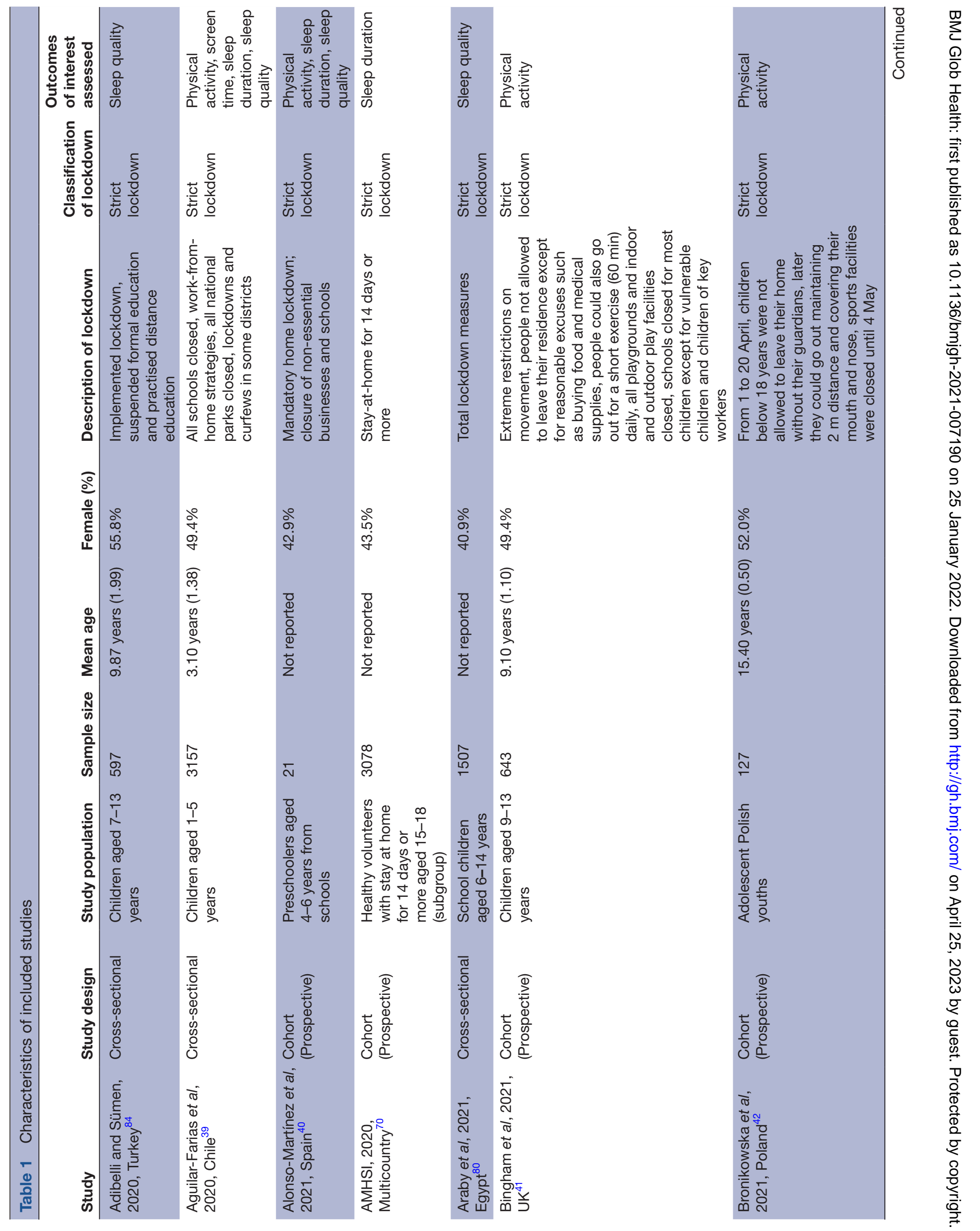




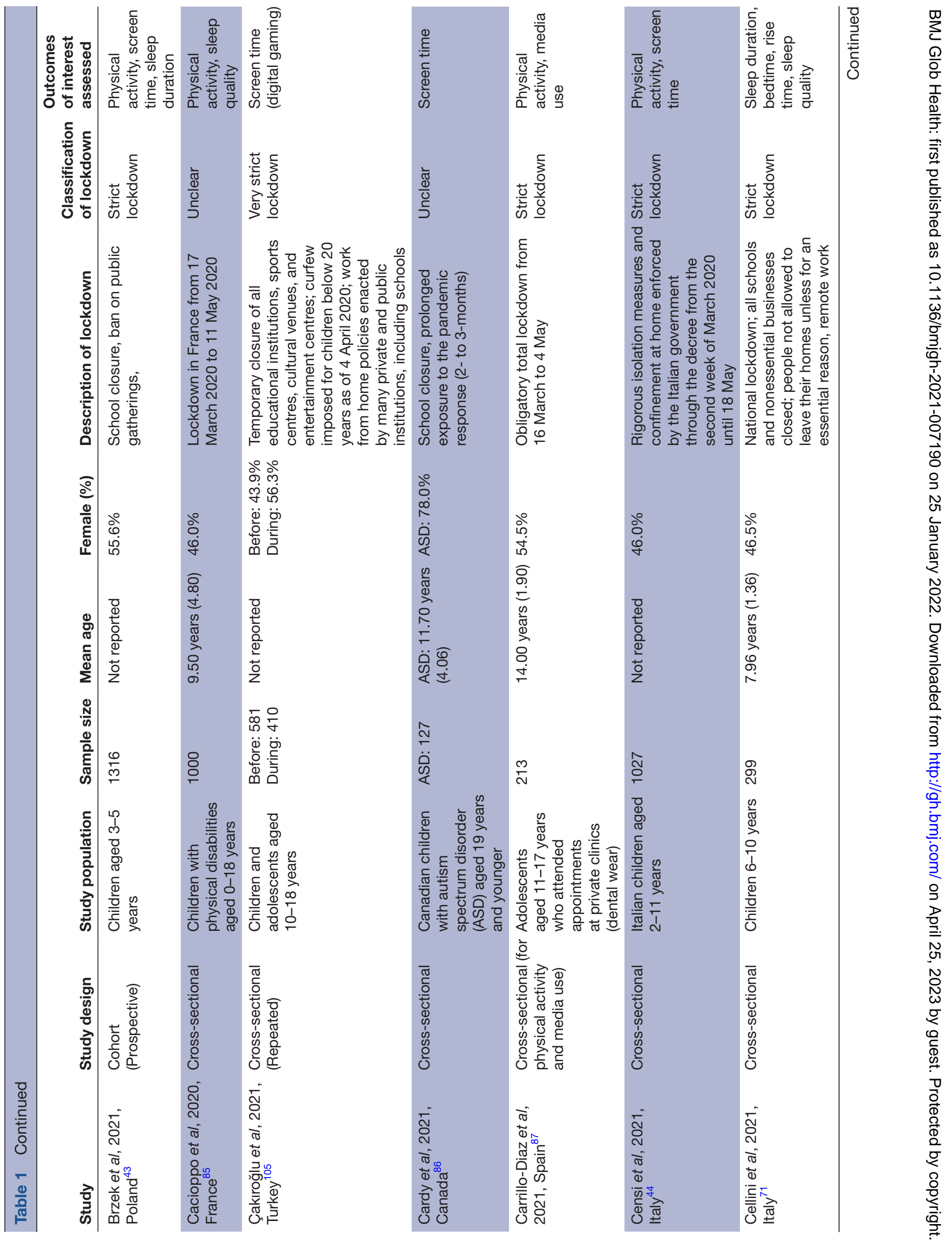




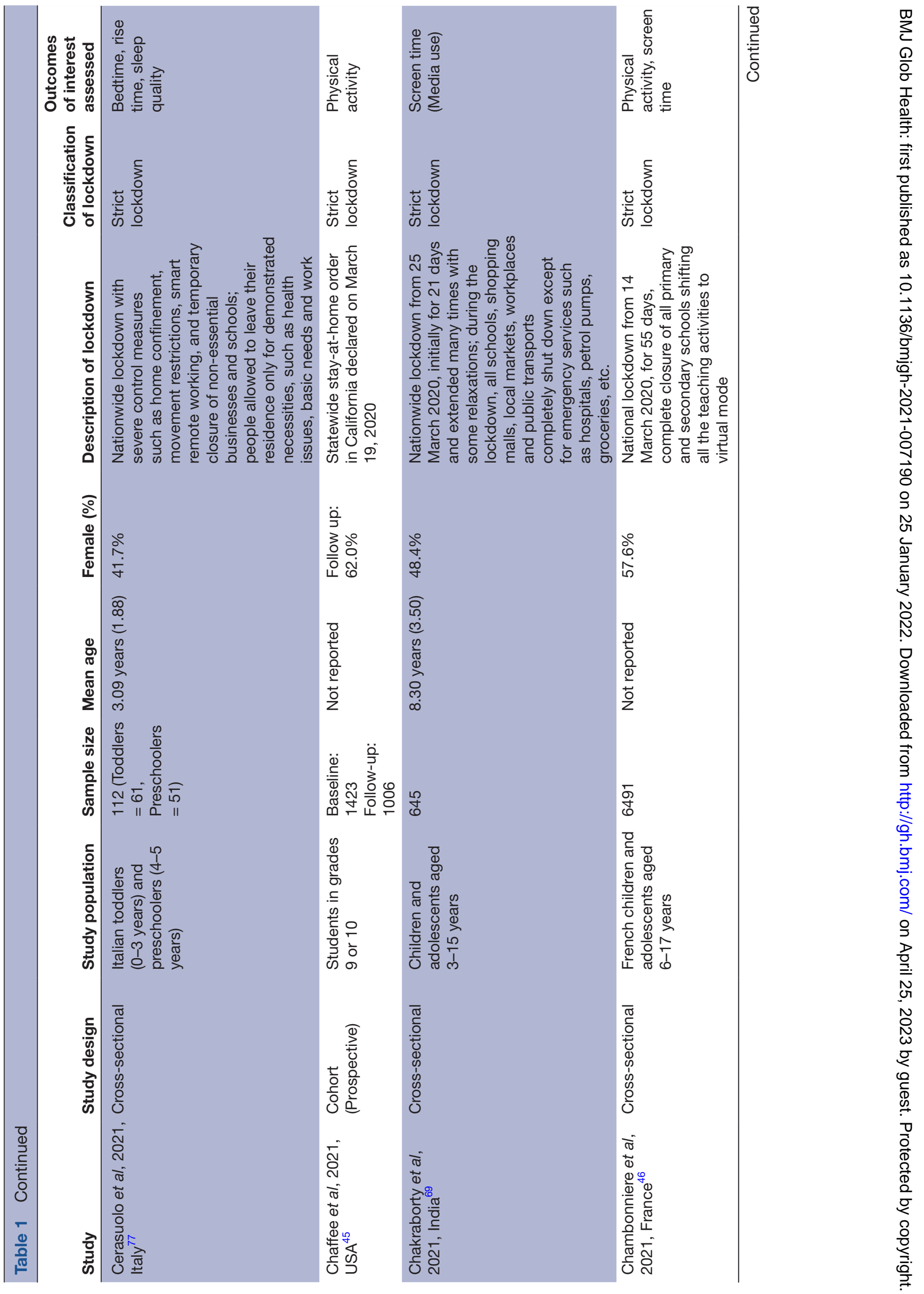




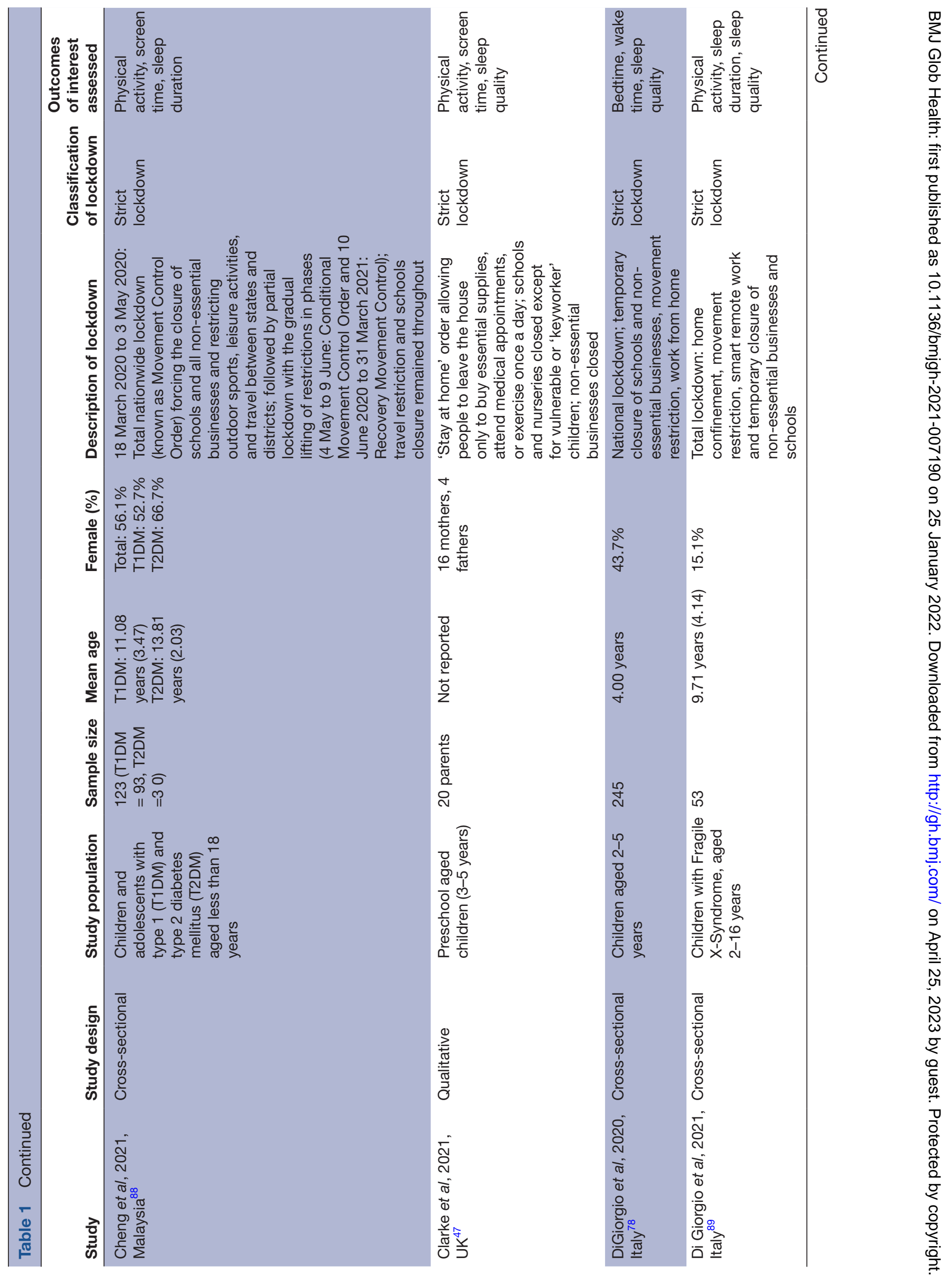




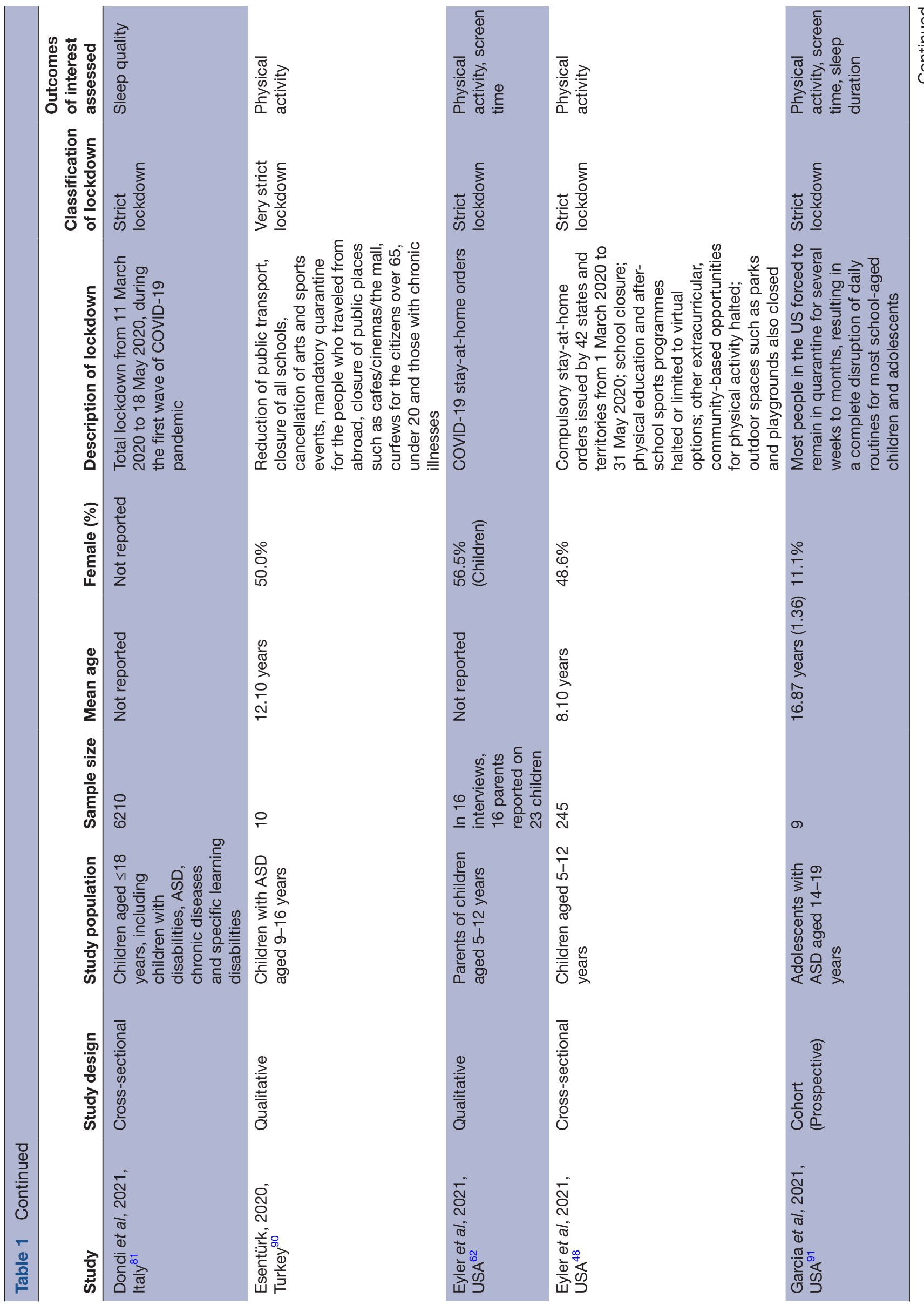

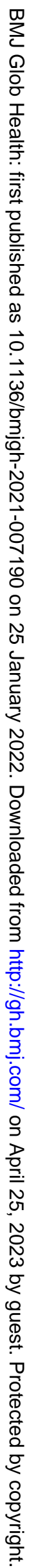




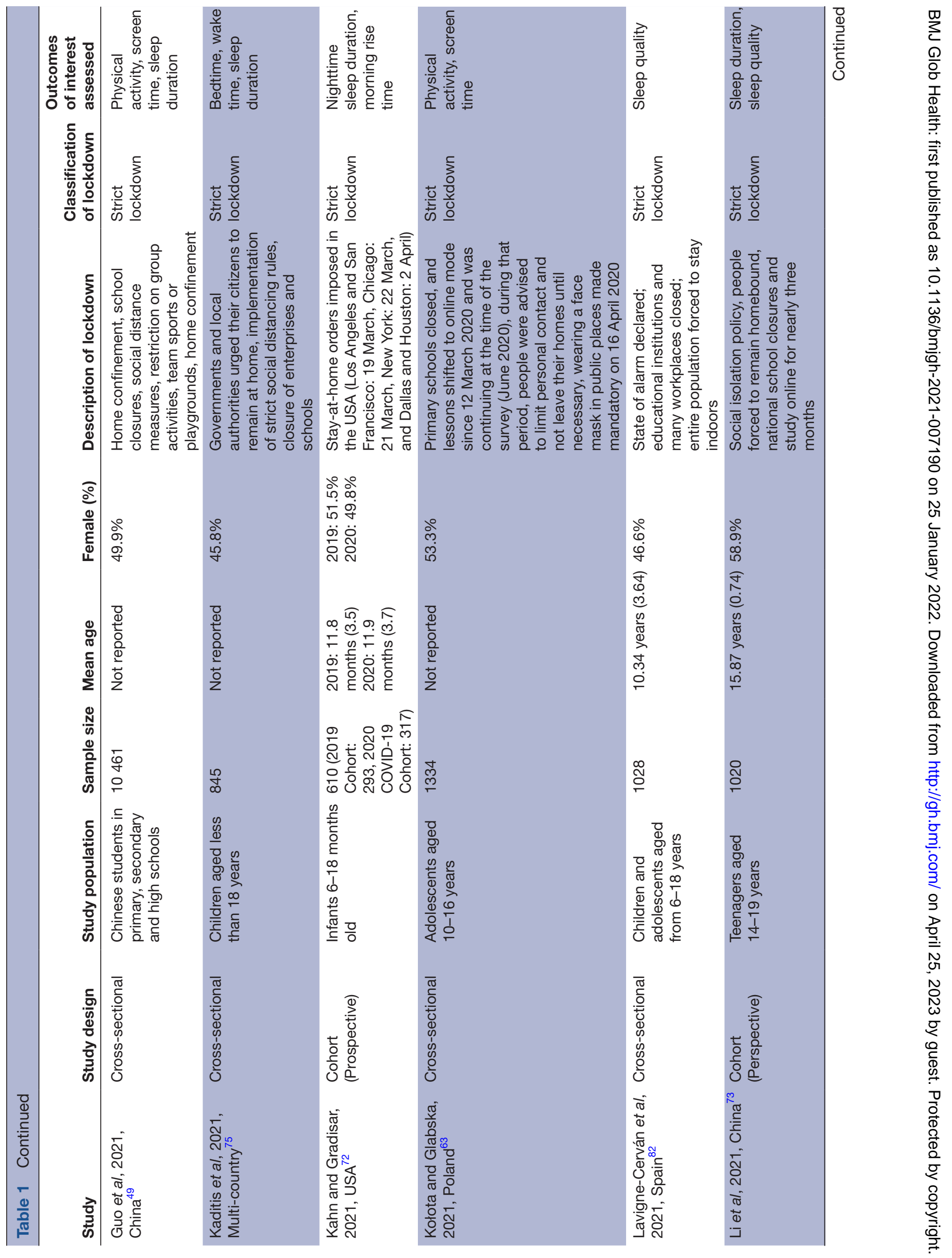




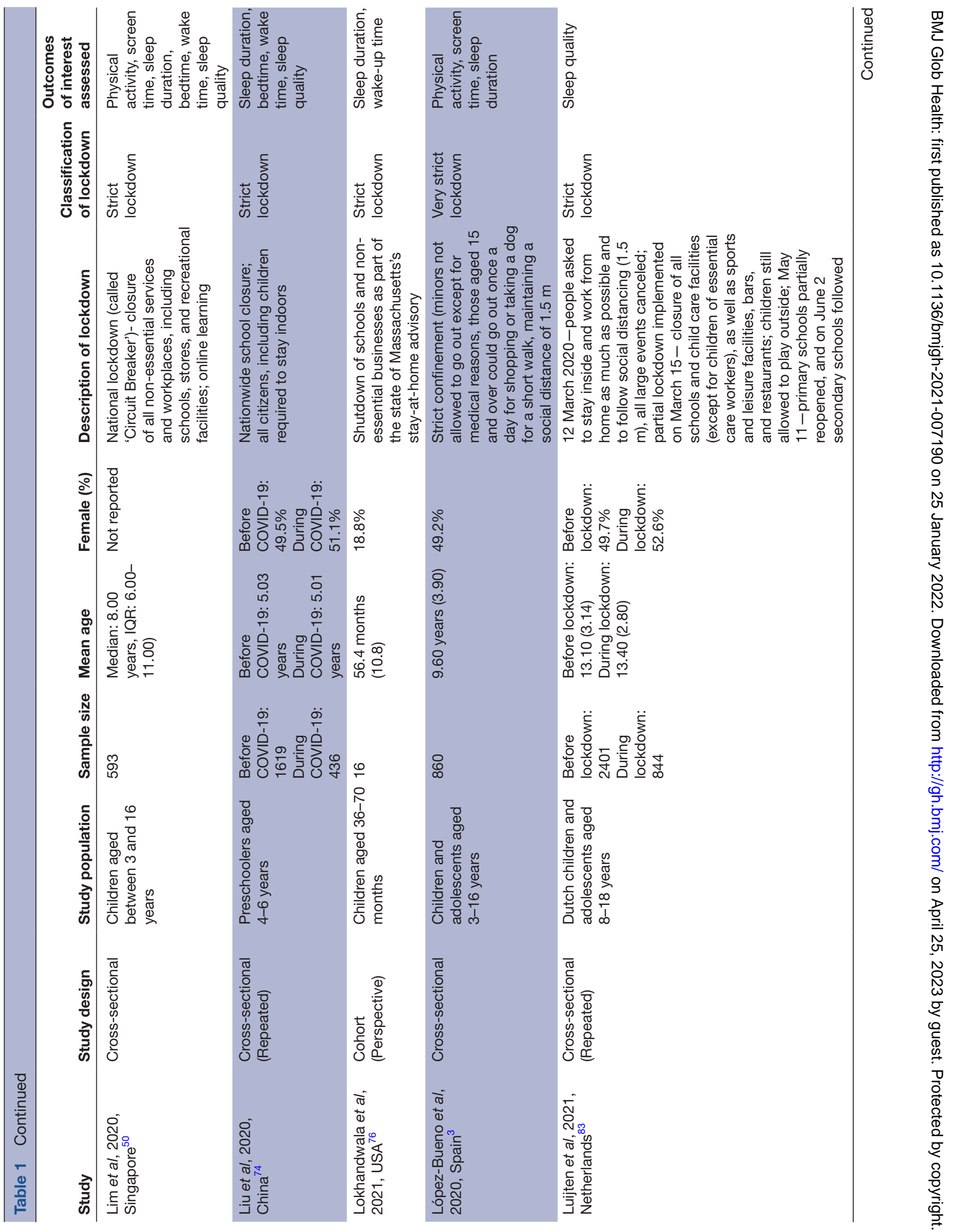




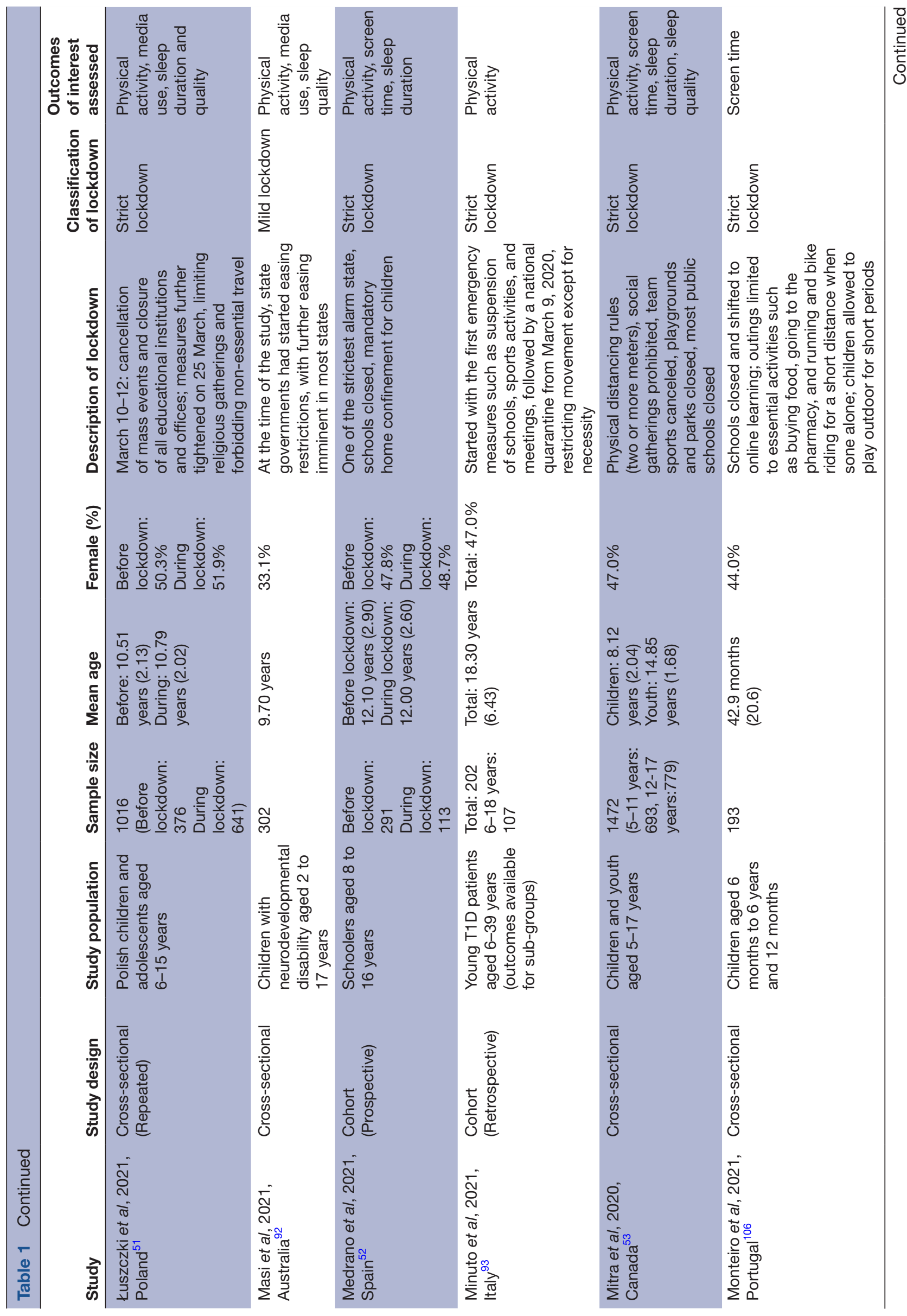




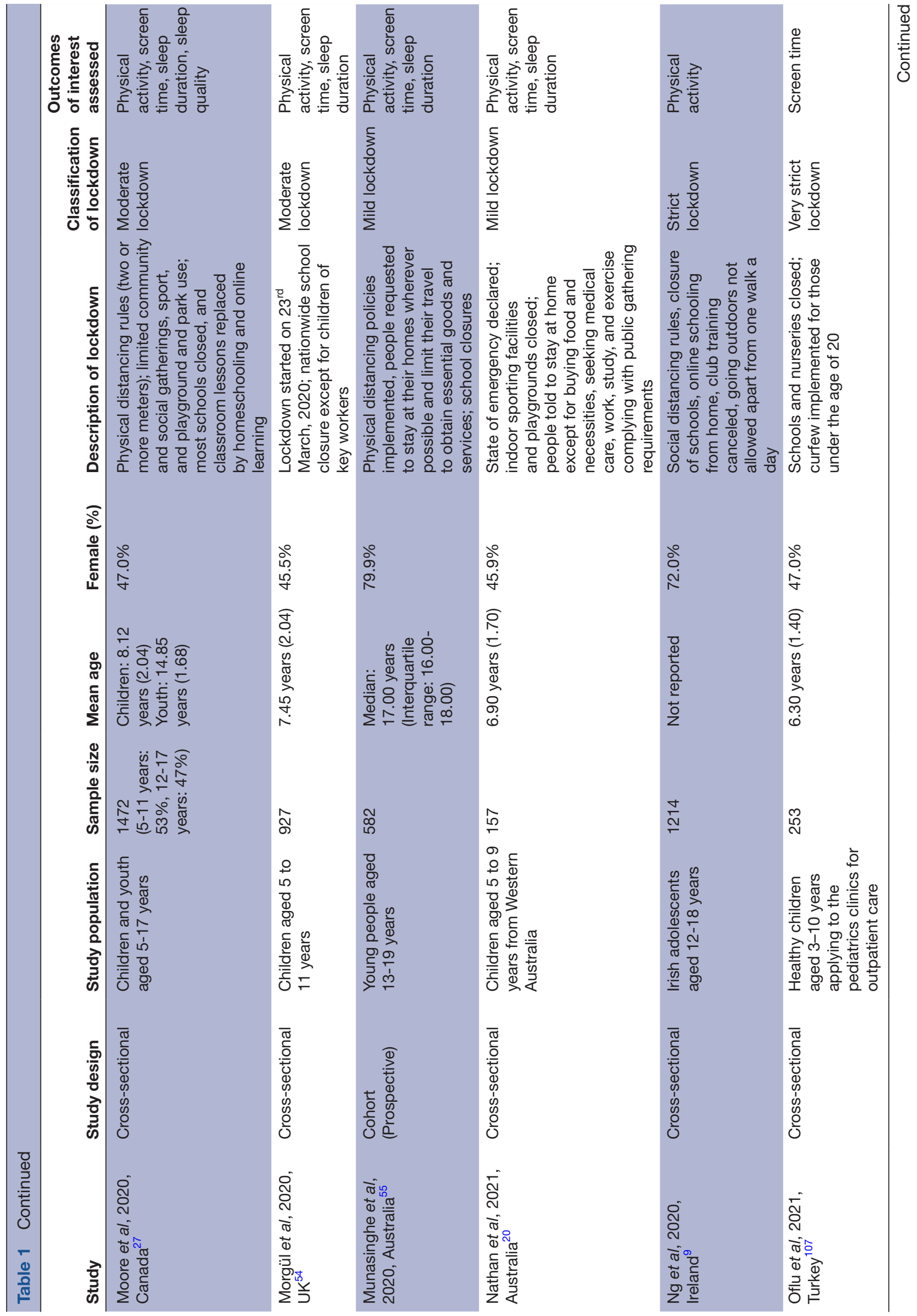




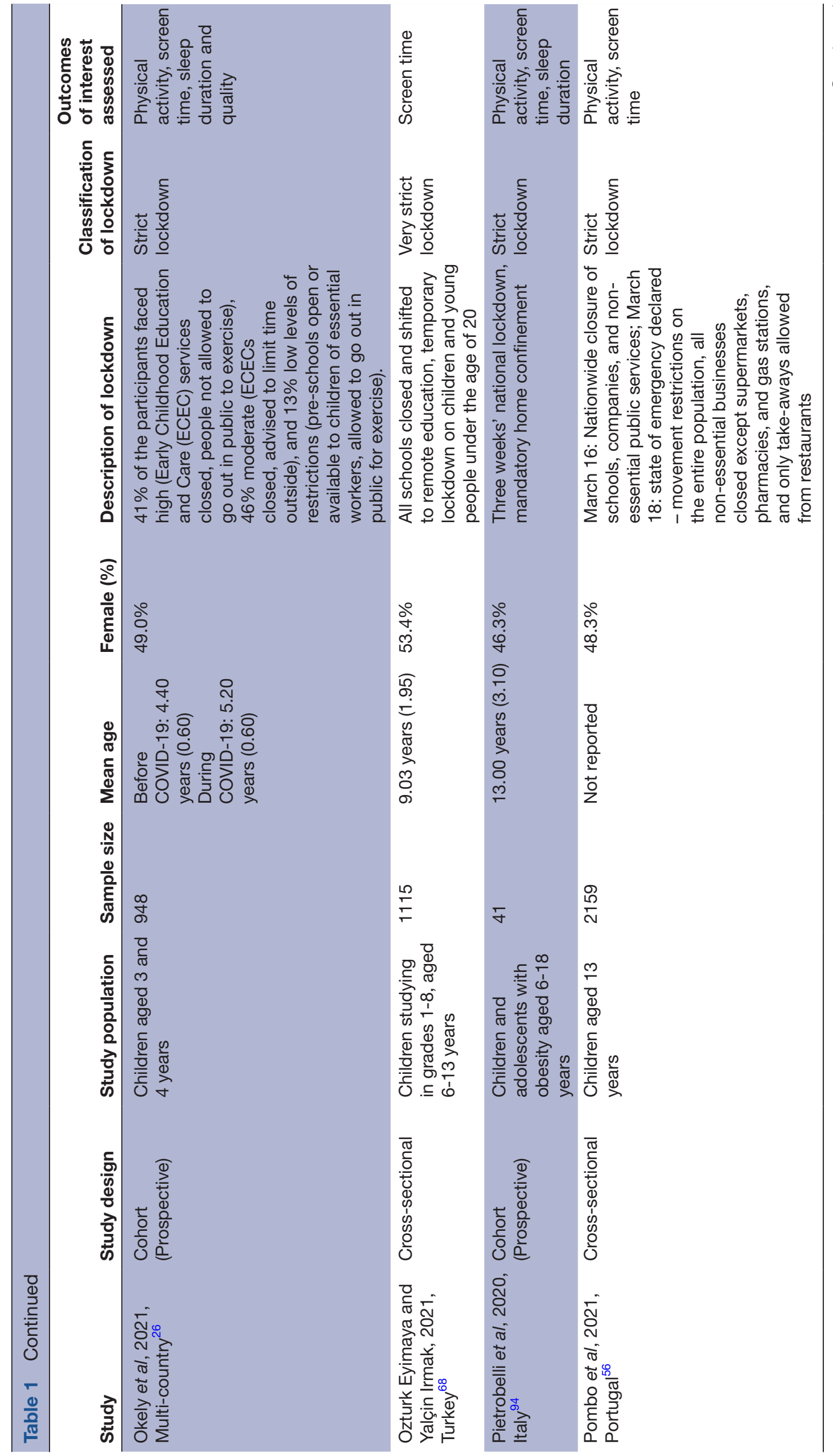




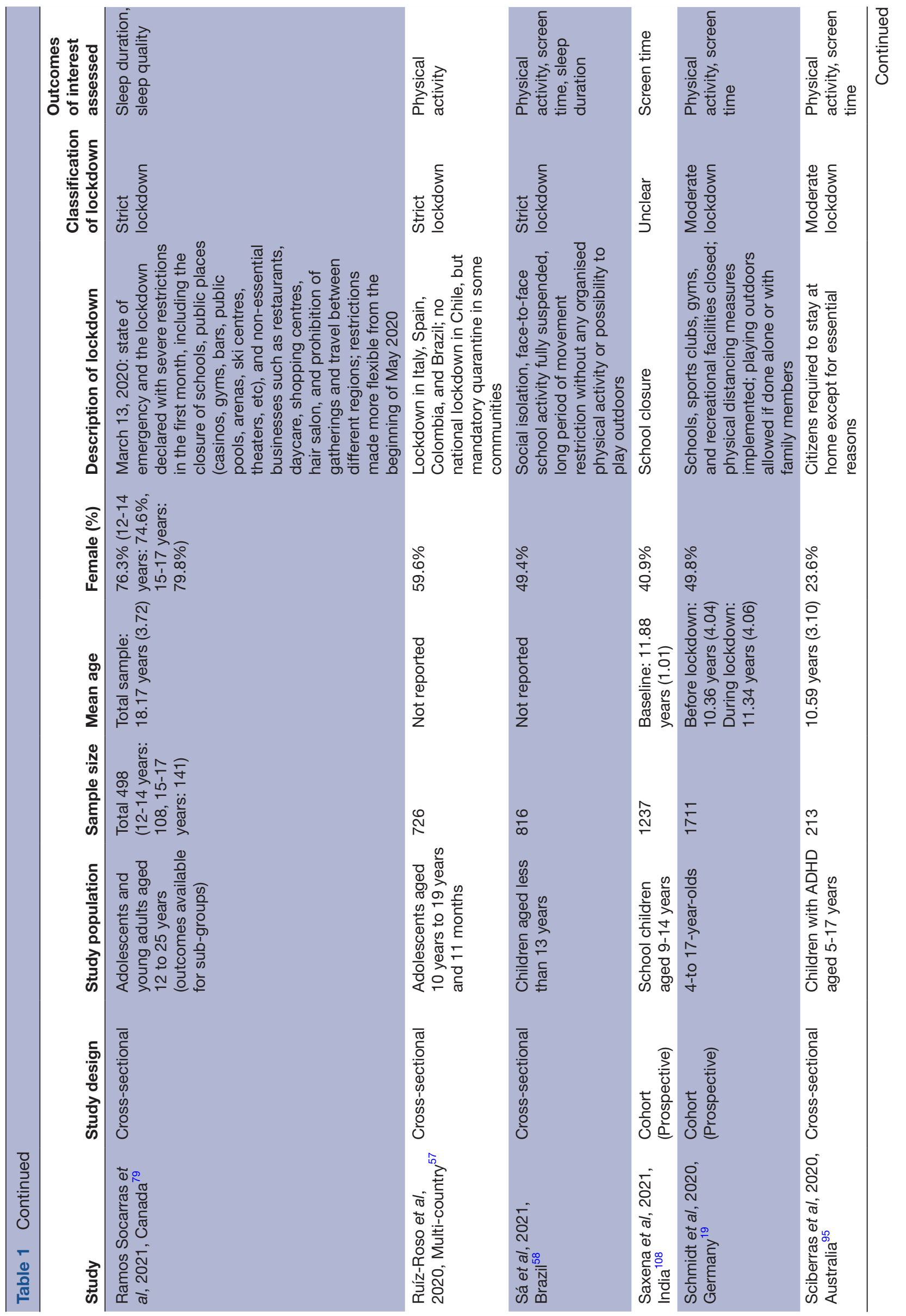




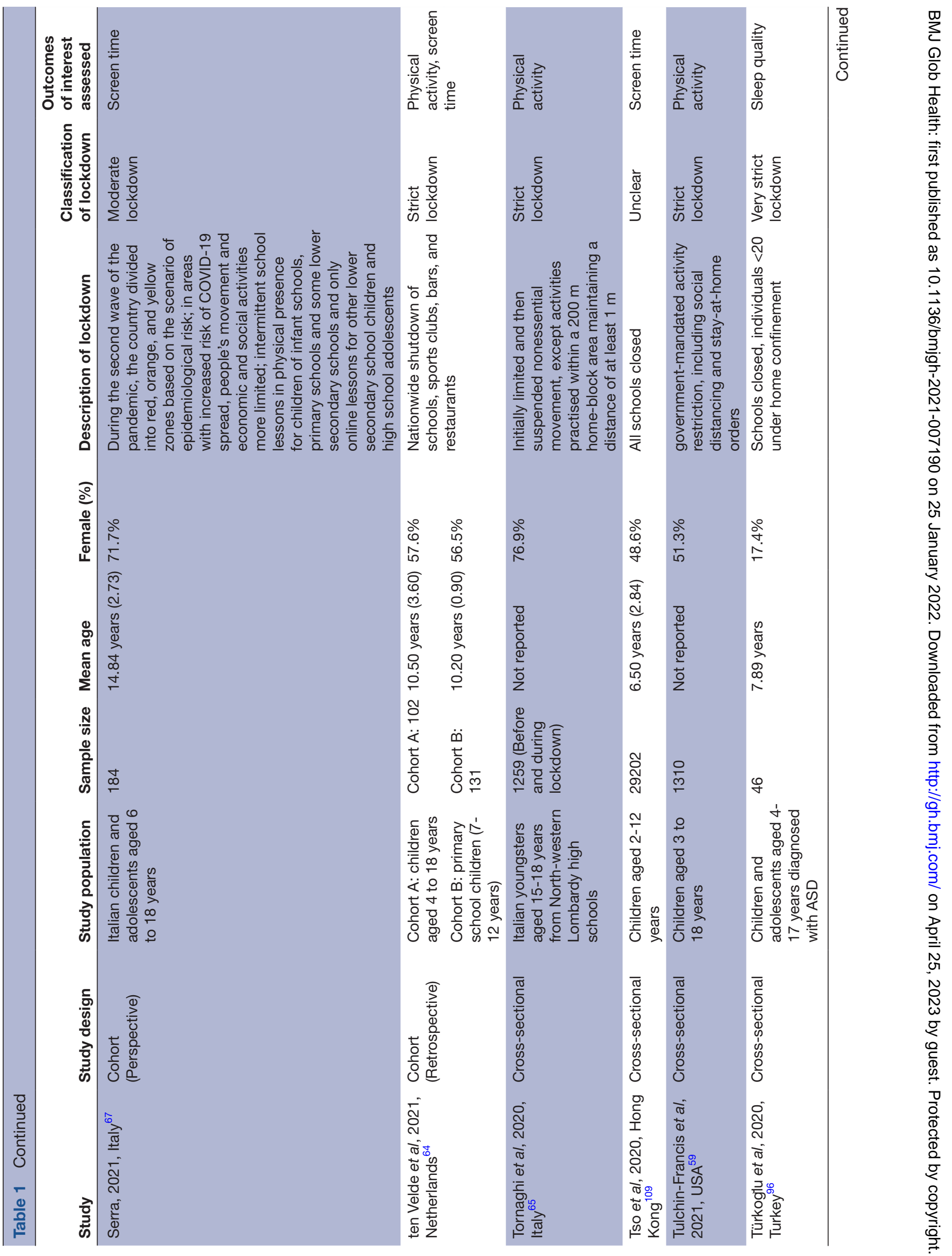




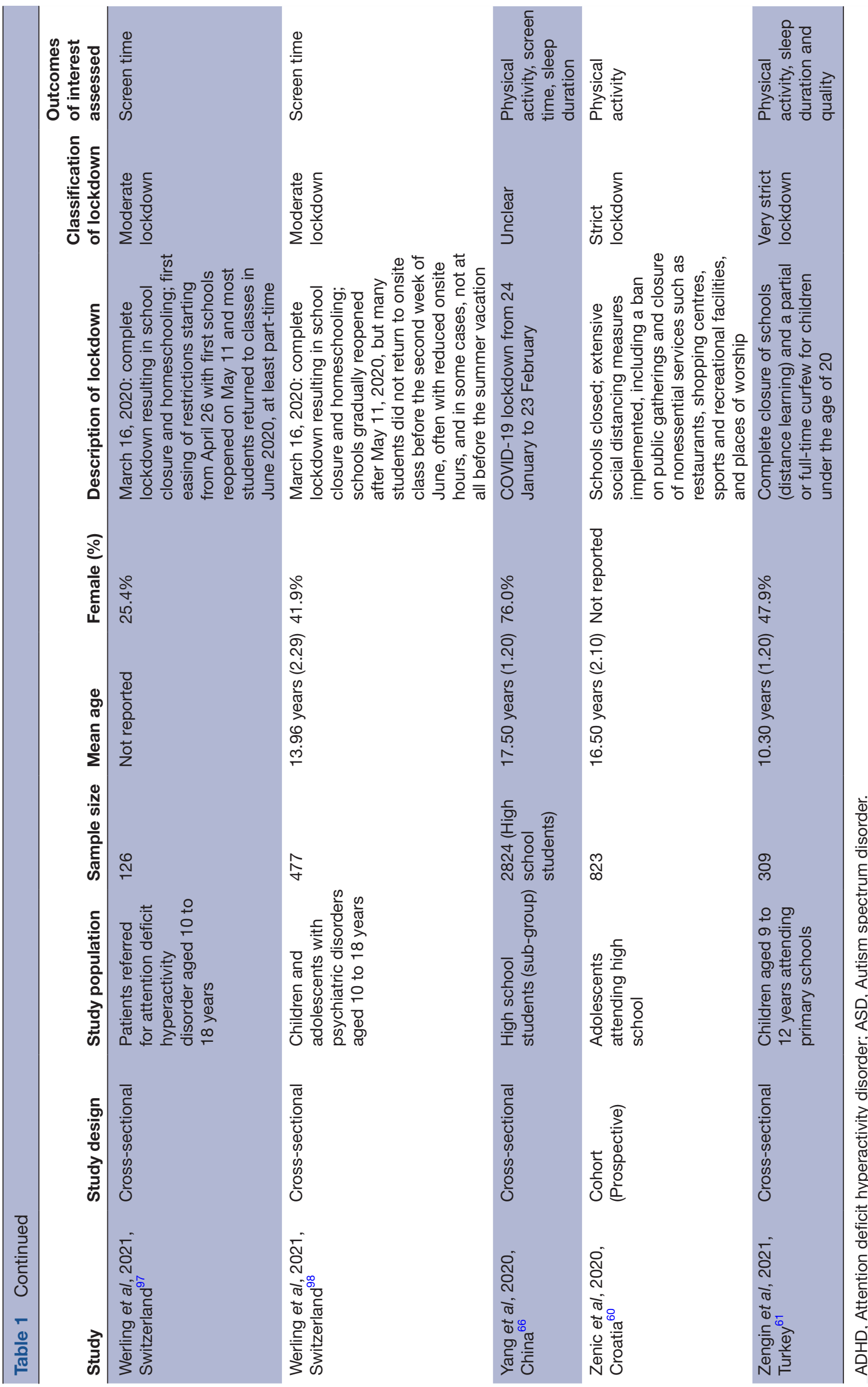

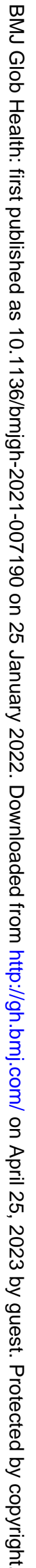




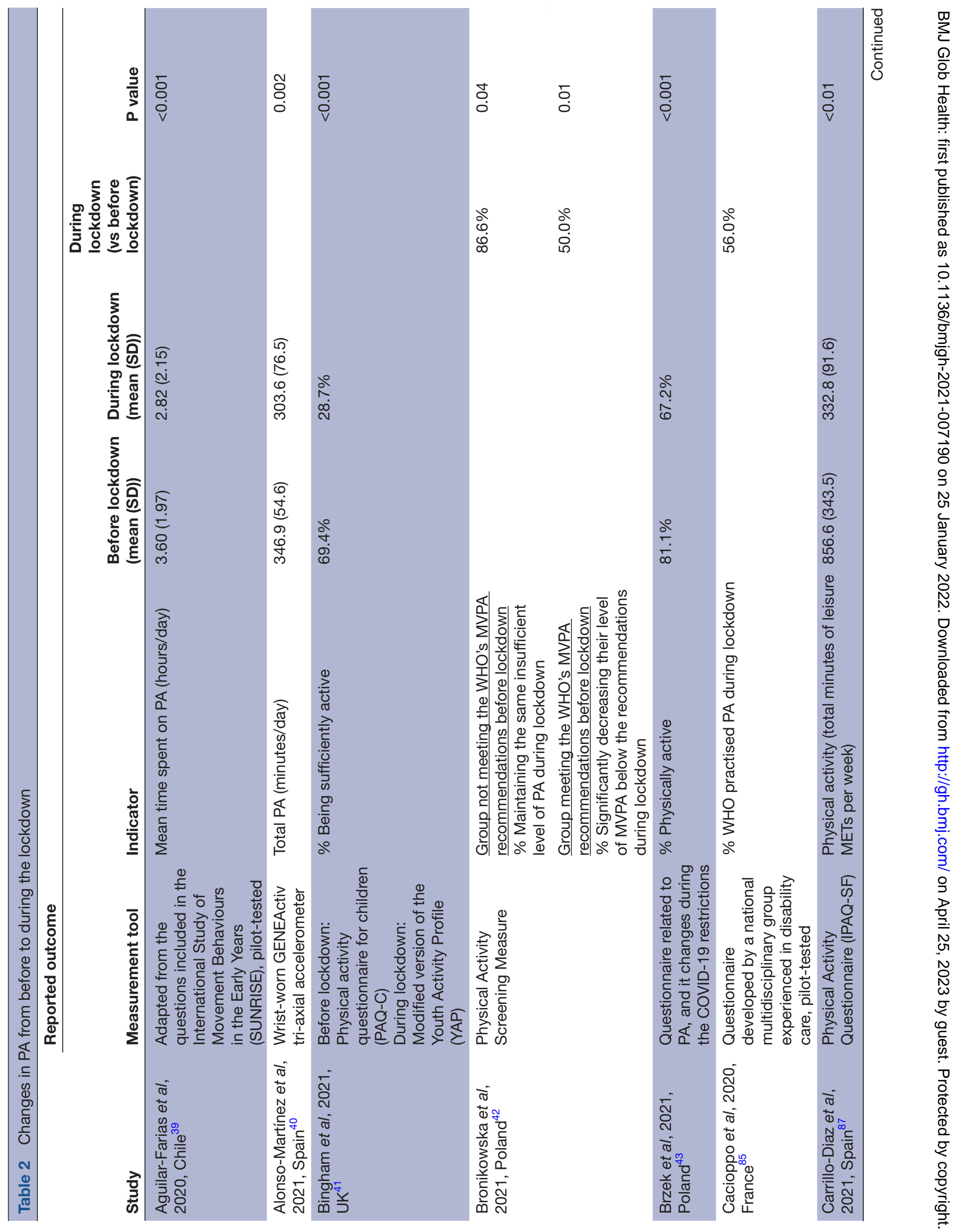




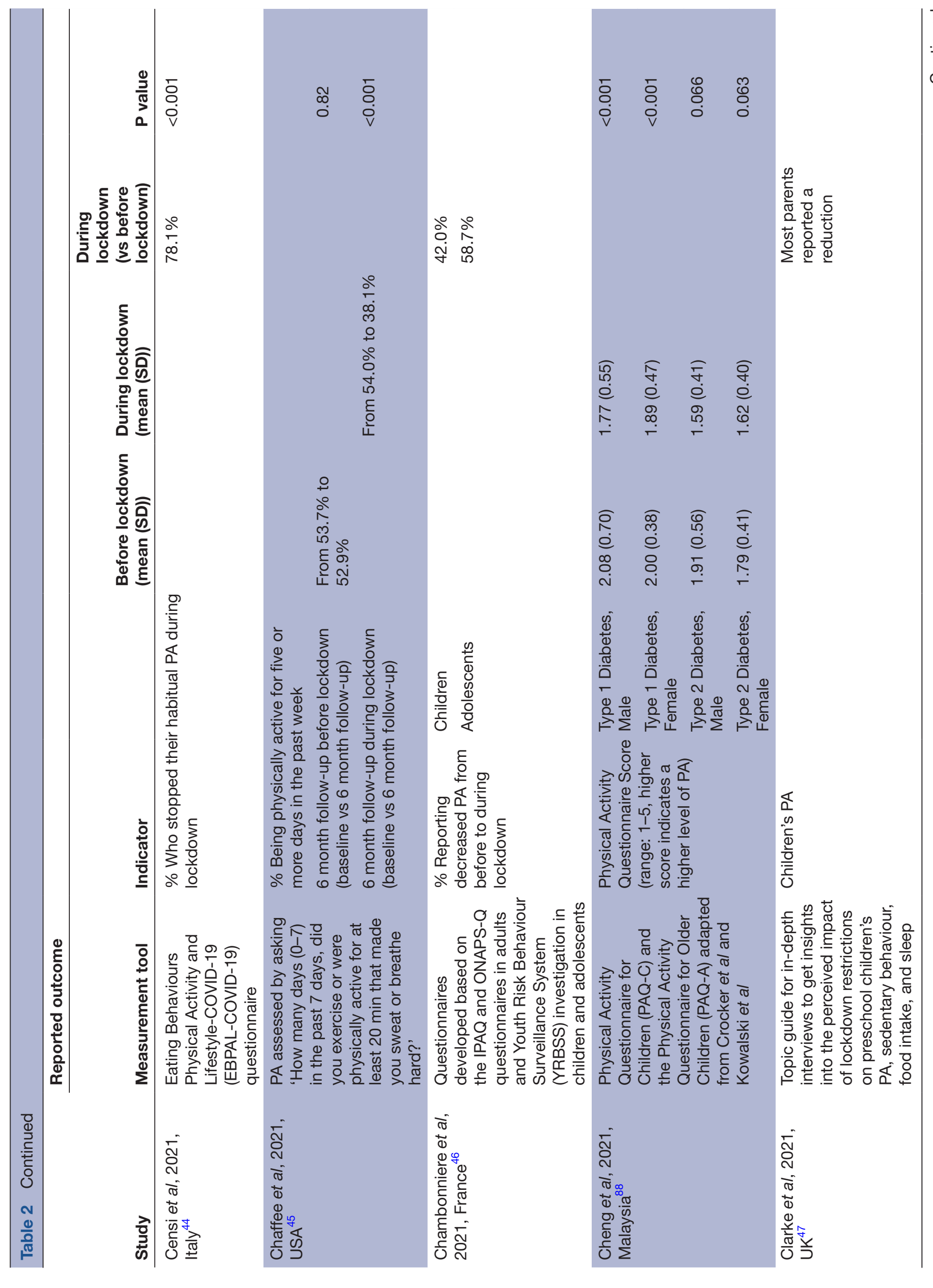



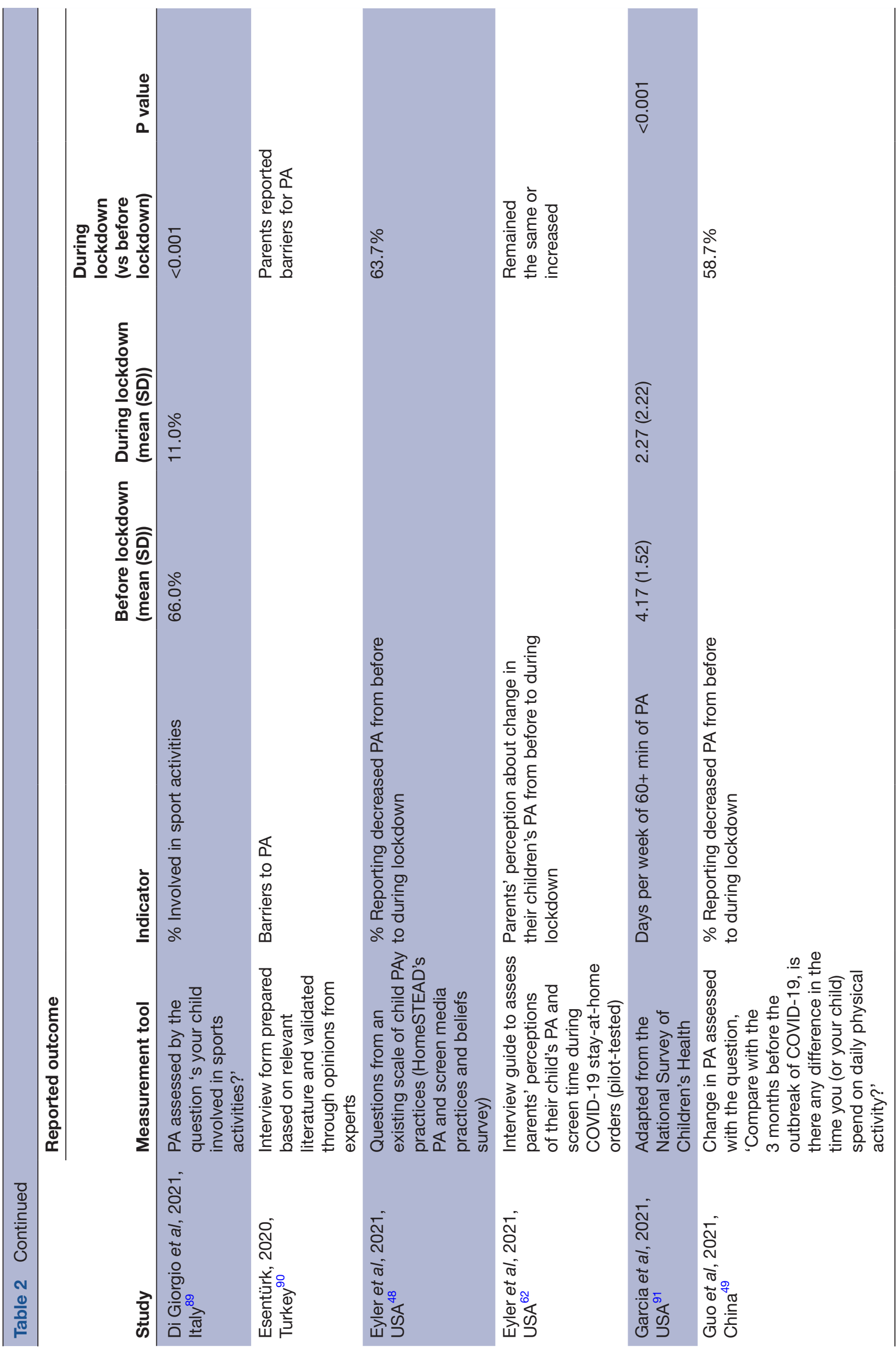


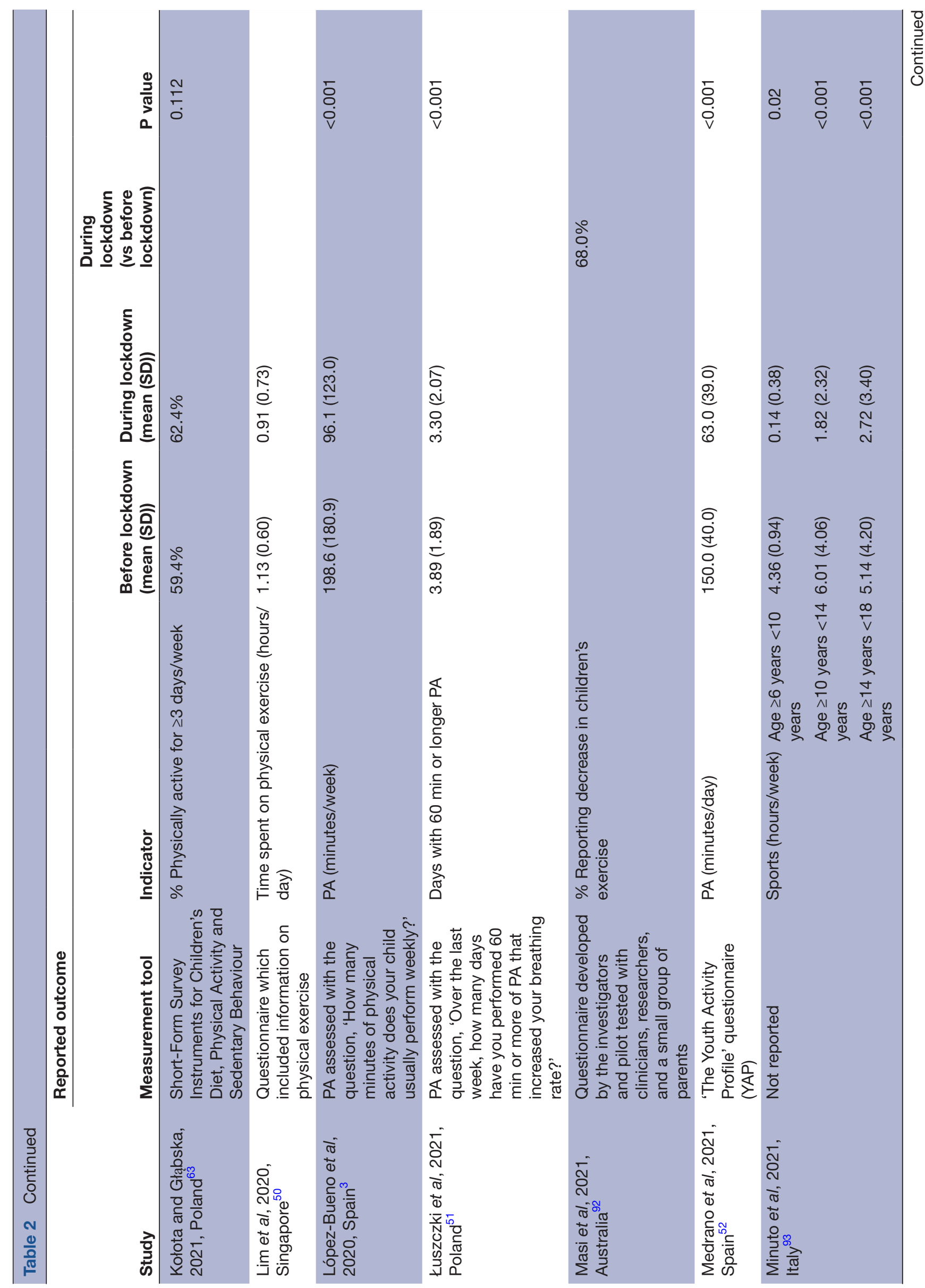

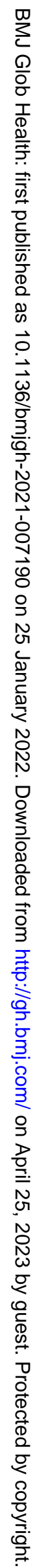




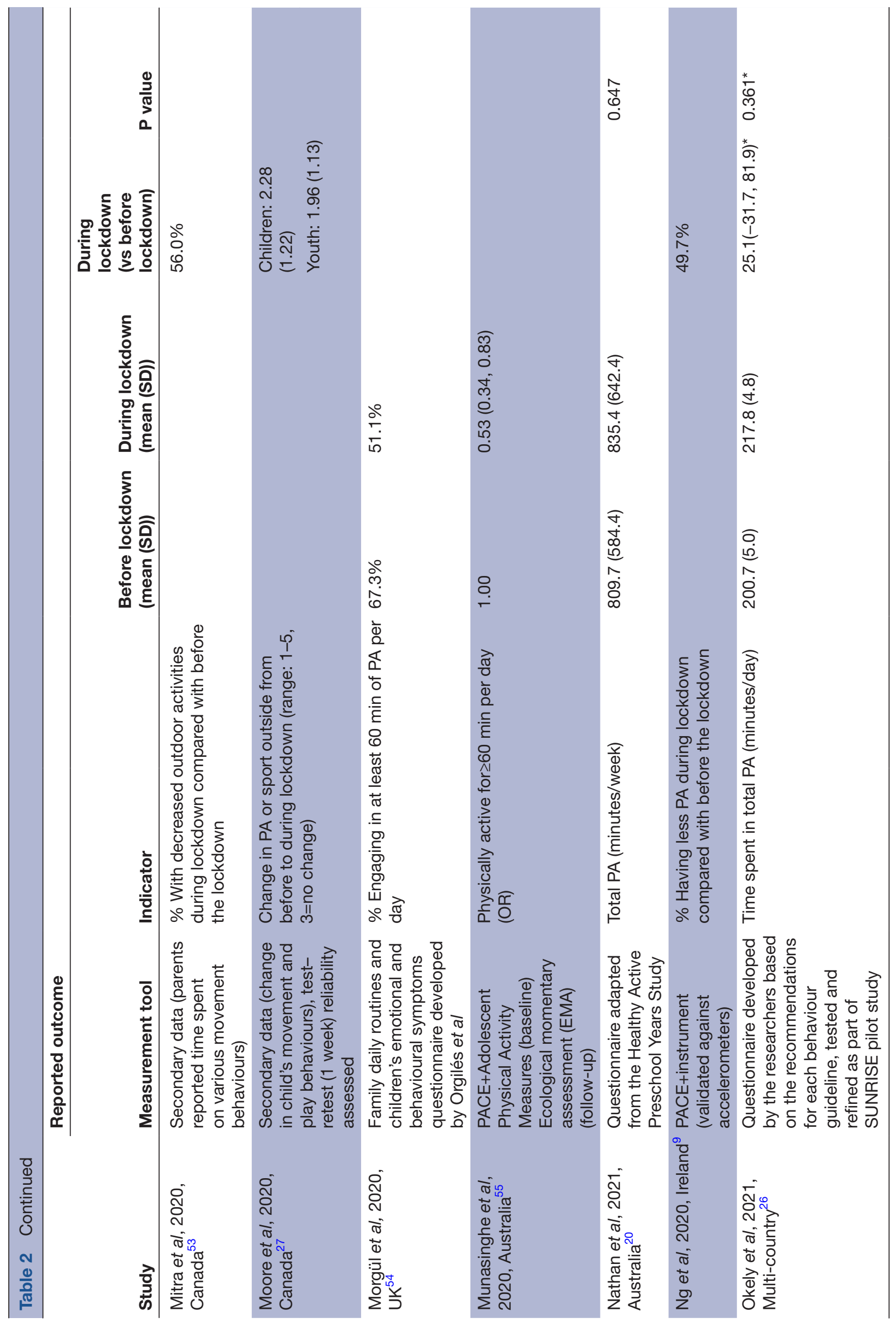




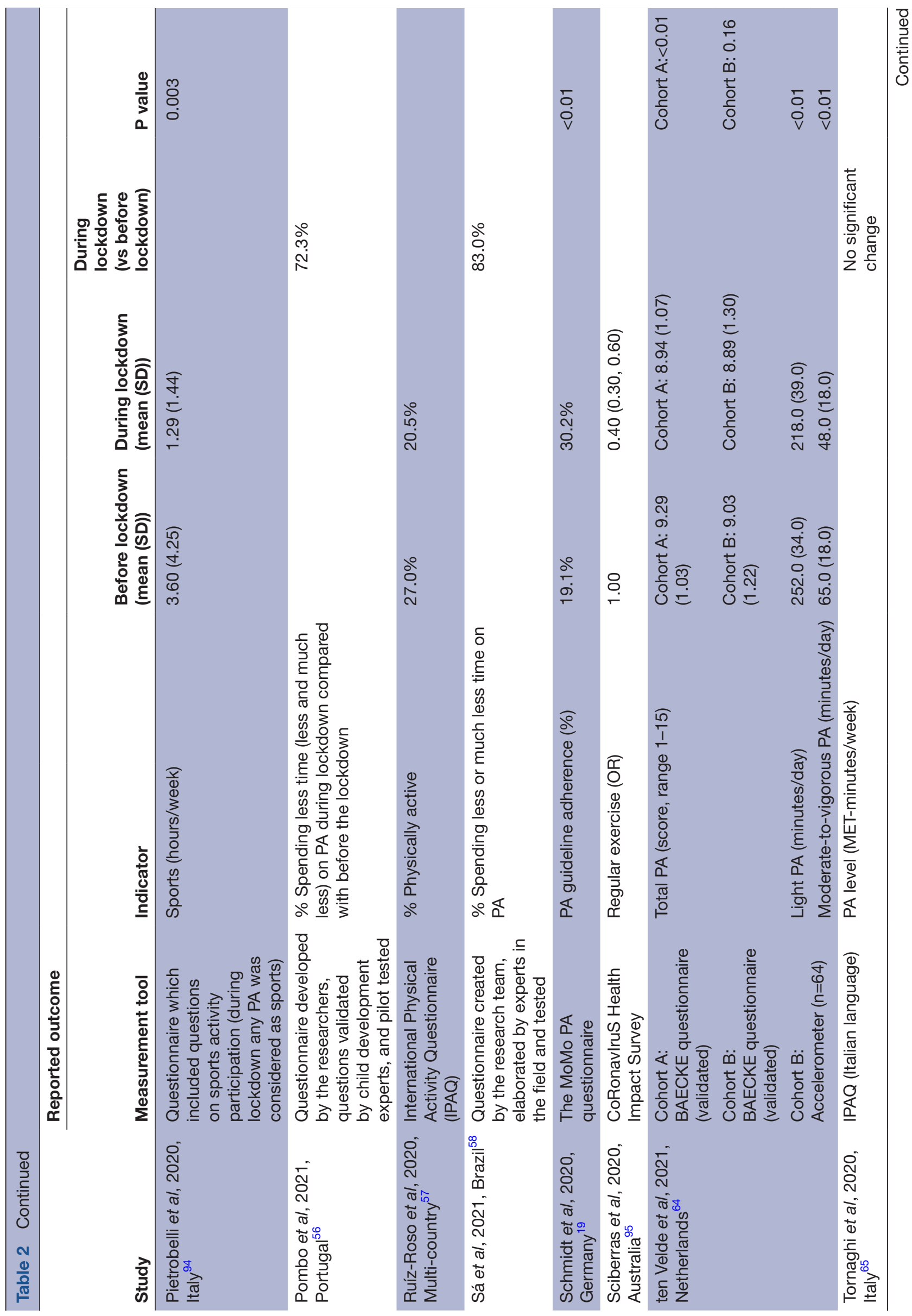

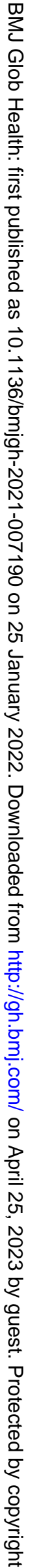


(both cross-sectional $)^{51}{ }^{54}$ reported a decrease, and eleven (four cohort and seven cross-sectional) ${ }^{320264049535556587576}$ reported no significant change in sleep duration. The increase in daily sleep duration among children and adolescents ranged from $11 \mathrm{~min}$ in Chile and the USA to approximately 1 hour in a multicountry study. ${ }^{39} 7072$ Spanish children slept approximately 48 min more on weekdays and approximately $42 \mathrm{~min}$ more on weekends during the COVID-19 confinement. ${ }^{52}$ Similar results were observed among preschoolers in China. ${ }^{74}$ Italian and Singaporean children slept approximately $27 \mathrm{~min}$ and 20 min more, respectively, during the lockdown than before the lockdown. ${ }^{50}$ Studies from the UK and Poland reported that children slept less during the lockdown than before the lockdown. ${ }^{51} 54$ Two multicountry studies and studies from Spain, Australia, the USA, Portugal and China did not observe any significant difference in sleep duration among children and adolescents from before to during the lockdown. ${ }^{32026404955567576}$

Ten studies ${ }^{26} 506171$ 73-75 77-79 compared bedtime and wake-up time and one more study ${ }^{72}$ compared wake-up time before and during the lockdown. All of them reported that children and adolescents went to bed later and woke up later during the COVID-19 lockdown than before the lockdown, except three studies, of which one ${ }^{61}$ reported no change in wake-up time and two ${ }^{77} 79$ reported no change in wake-up time on weekend days from before to during the lockdown. In Italy, children's bedtime and wake-up time shifted by $53 \mathrm{~min}$ and $66 \mathrm{~min}$, respectively. ${ }^{78}$ A similar shift in bedtime and wake-up time was observed among Singaporean children. ${ }^{50}$ A multicountry longitudinal study among children aged $3-5$ years observed that children went to bed $34 \mathrm{~min}$ later and woke up $59 \mathrm{~min}$ later. $^{26}$

\section{Sleep quality}

Changes in sleep quality from before to during the lockdown are presented in table 4 . Nineteen studies (4 cohort, 14 cross-sectional and 1 qualitative) reported changes in sleep quality from before to during the COVID-19 lockdown. Eight (one cohort, six cross-sectional and one qualitative) $)^{39} 40477180-83$ of them observed a decrease, five (one cohort and four cross-sectional) 2751737479 observed an increase and six (two cohort and four crosssectional) $265376-7884$ observed no significant change in sleep quality.

A decline in sleep quality was reported in studies from Chile, Spain, Turkey, Egypt, Italy, the UK and the Netherlands. ${ }^{39} 404771$ 80-83 In Chile, sleep quality among toddlers and preschoolers declined during the COVID-19 pandemic (sleep quality mean score: 5.68 before the pandemic vs 4.93 during the pandemic, $\mathrm{p}<0.001){ }^{39}$ Spanish preschoolers showed decreased sleep efficiency during the lockdown $(84.3 \%$ before the lockdown to $82.2 \%$ during the lockdown) ${ }^{40}$ A study among school children in Egypt reported that $49.6 \%$ had difficulty falling asleep, $42.6 \%$ woke up afraid and rushed to parents, $31.4 \%$ avoided bedtime and had frequent 


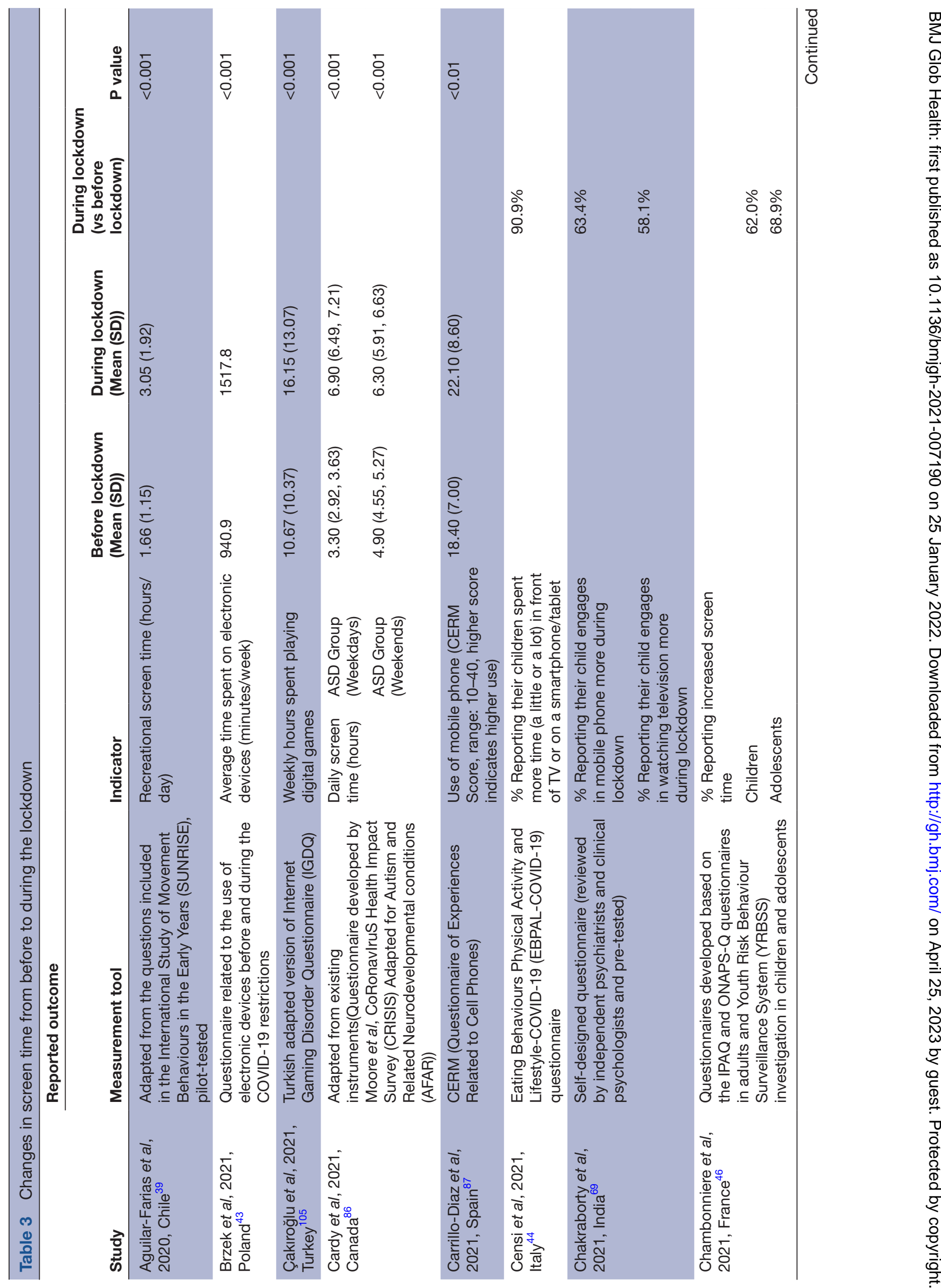




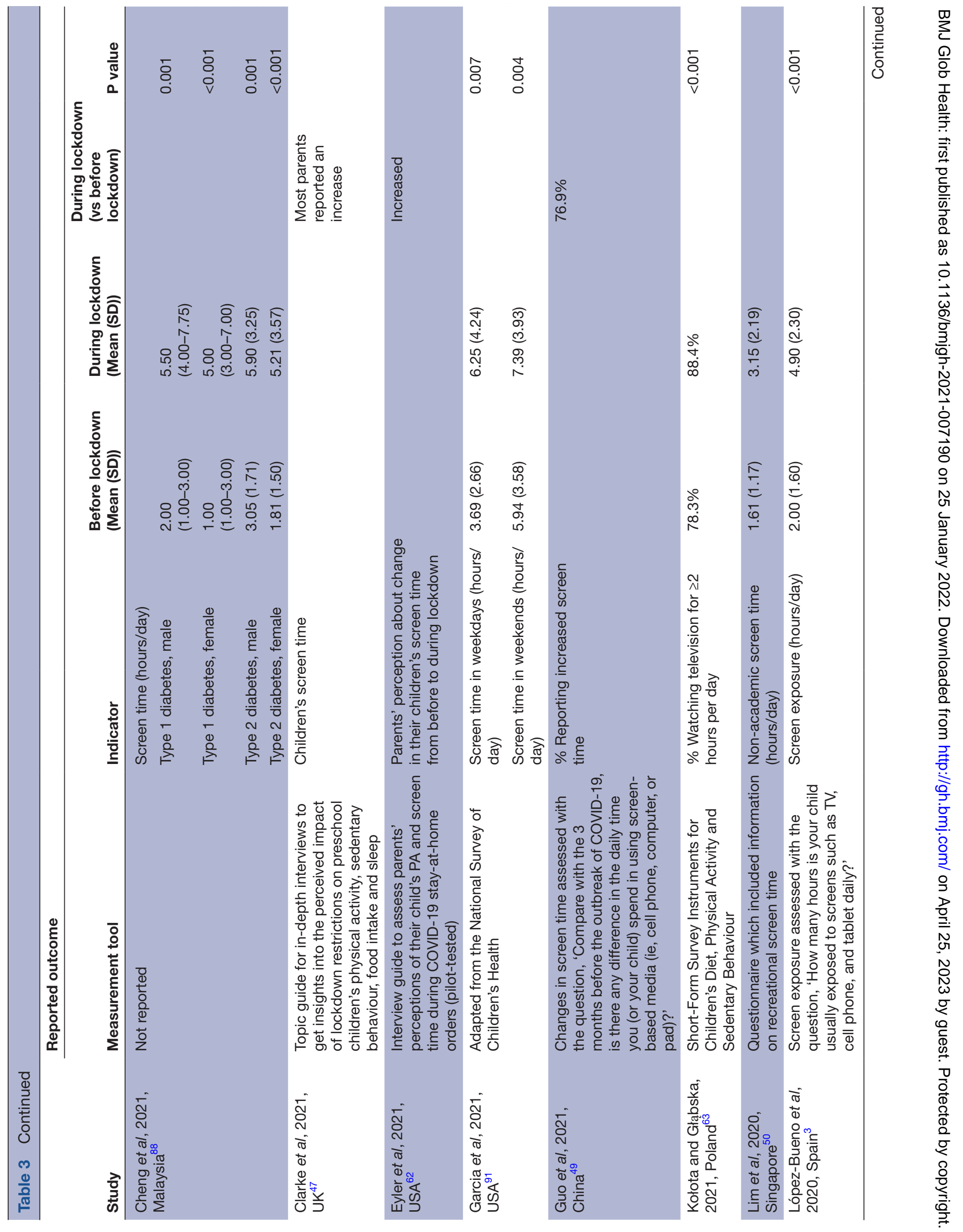




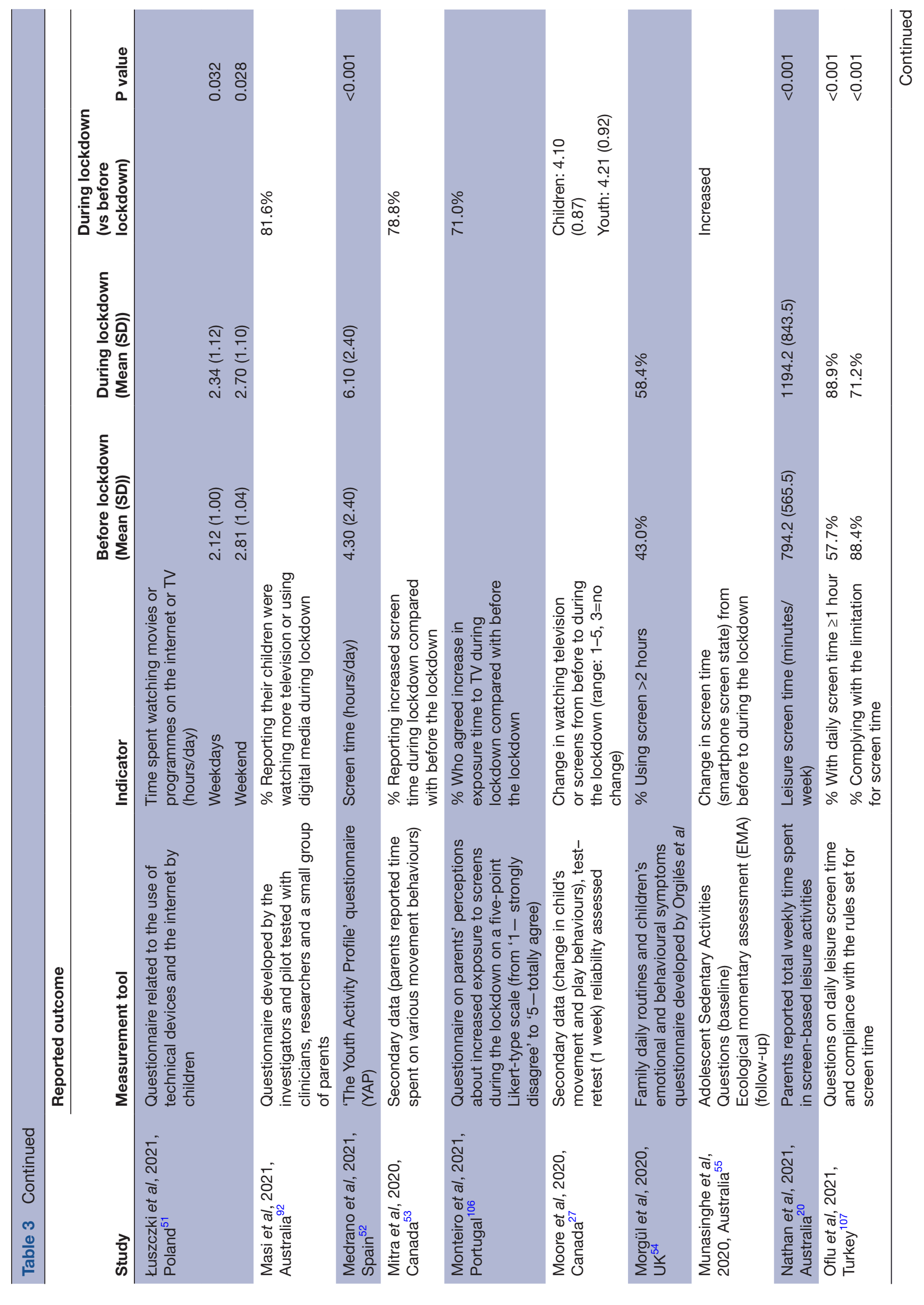




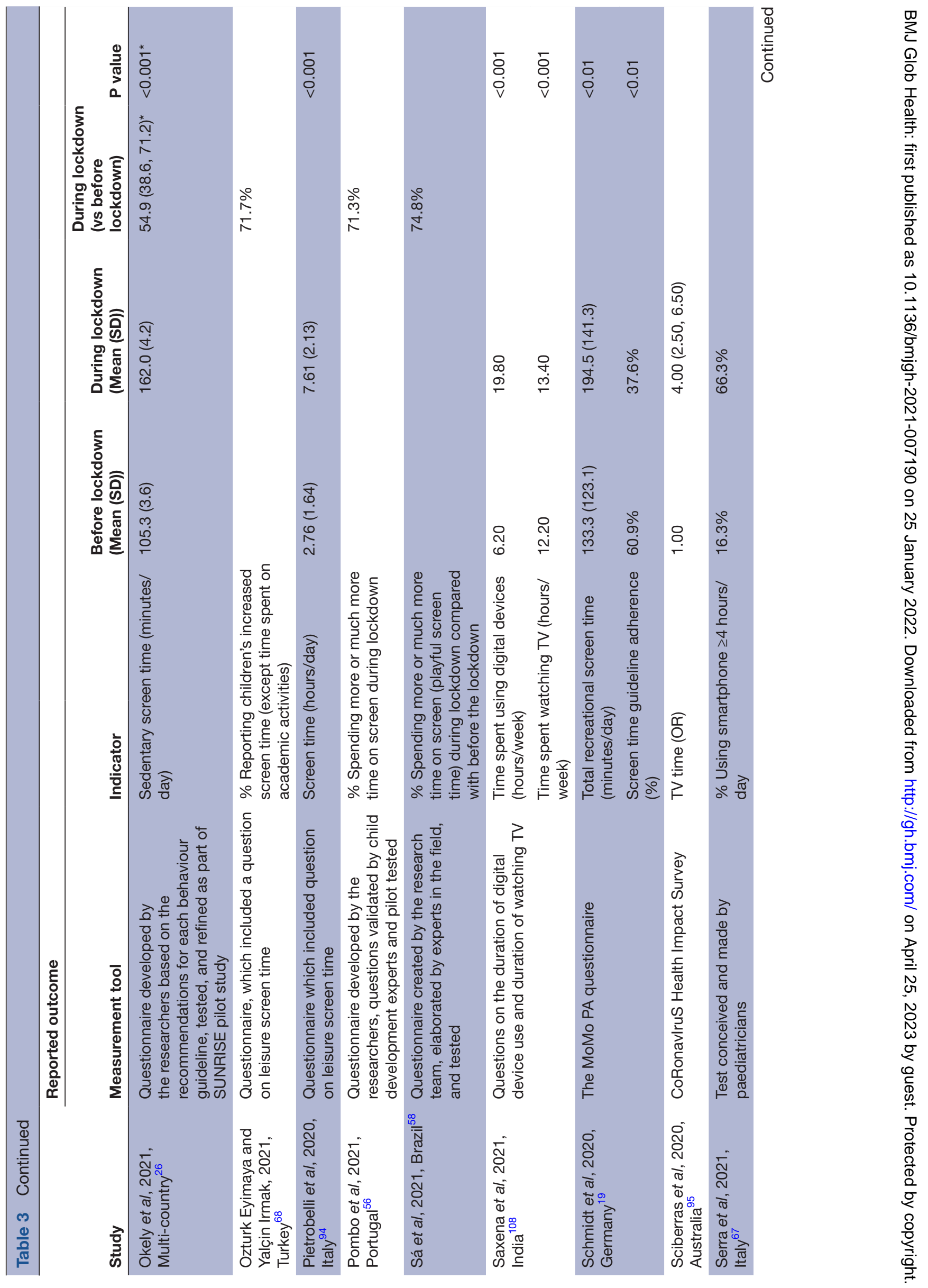




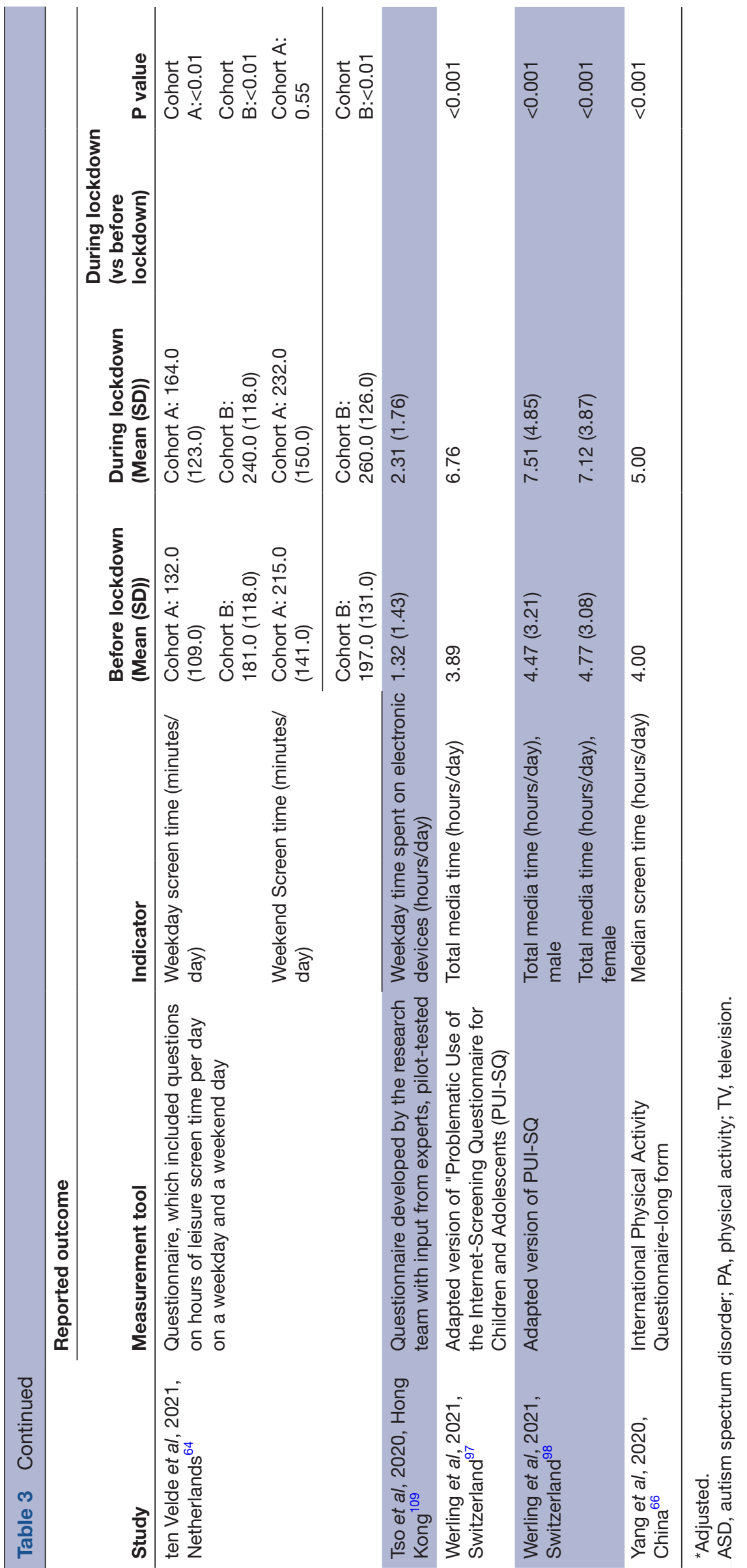

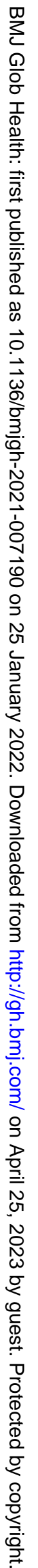




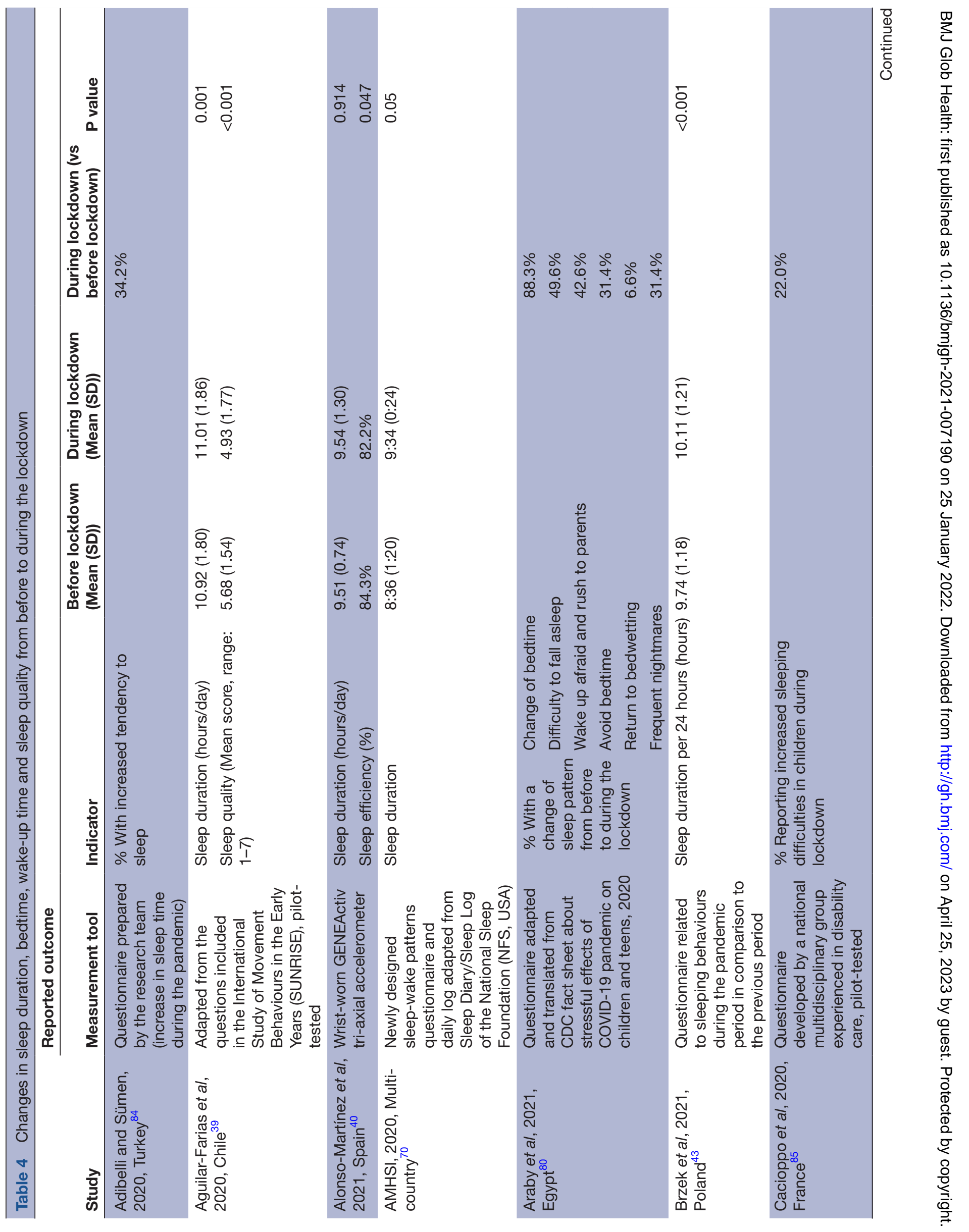




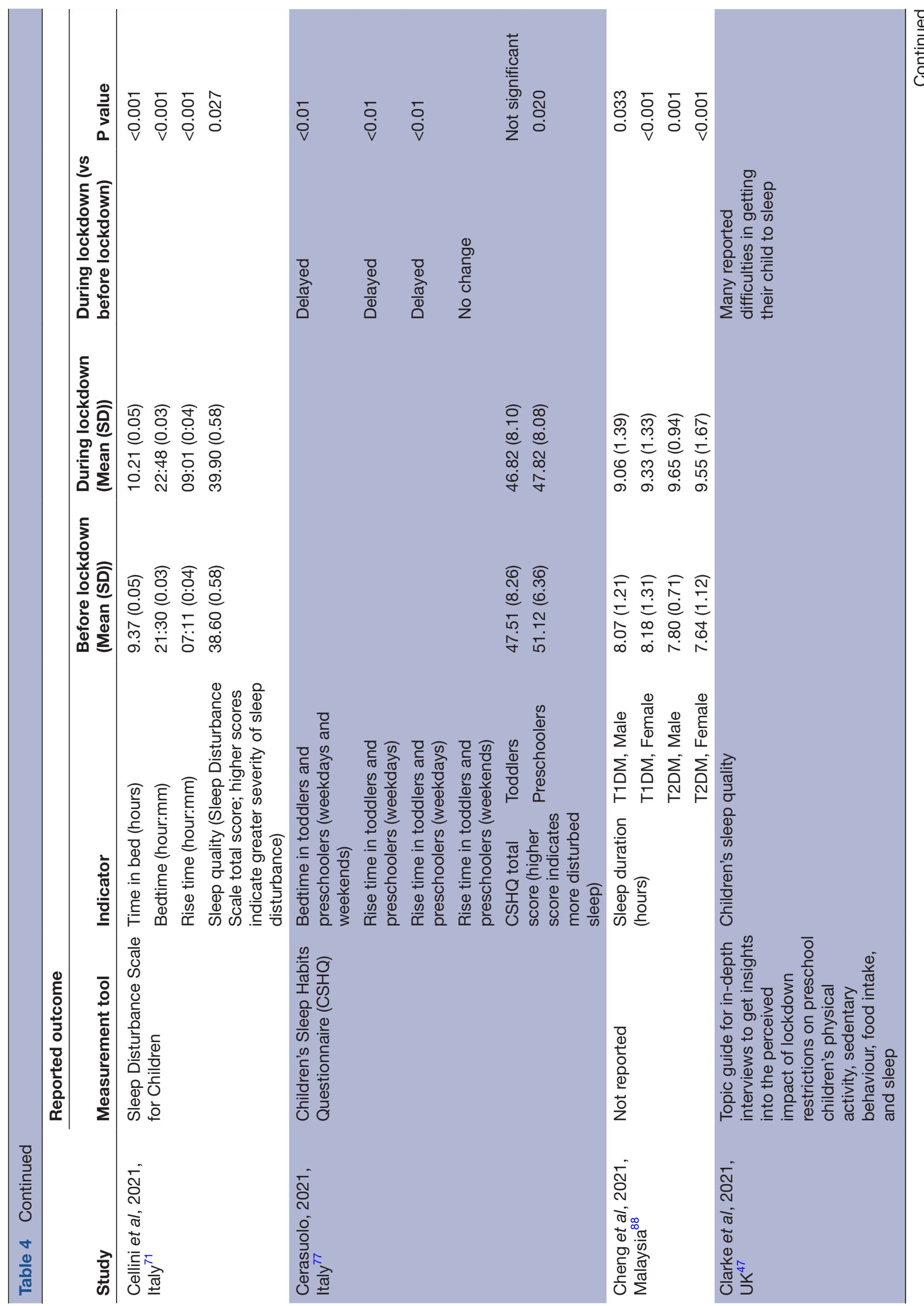

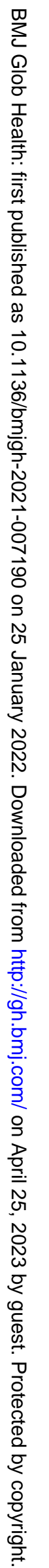




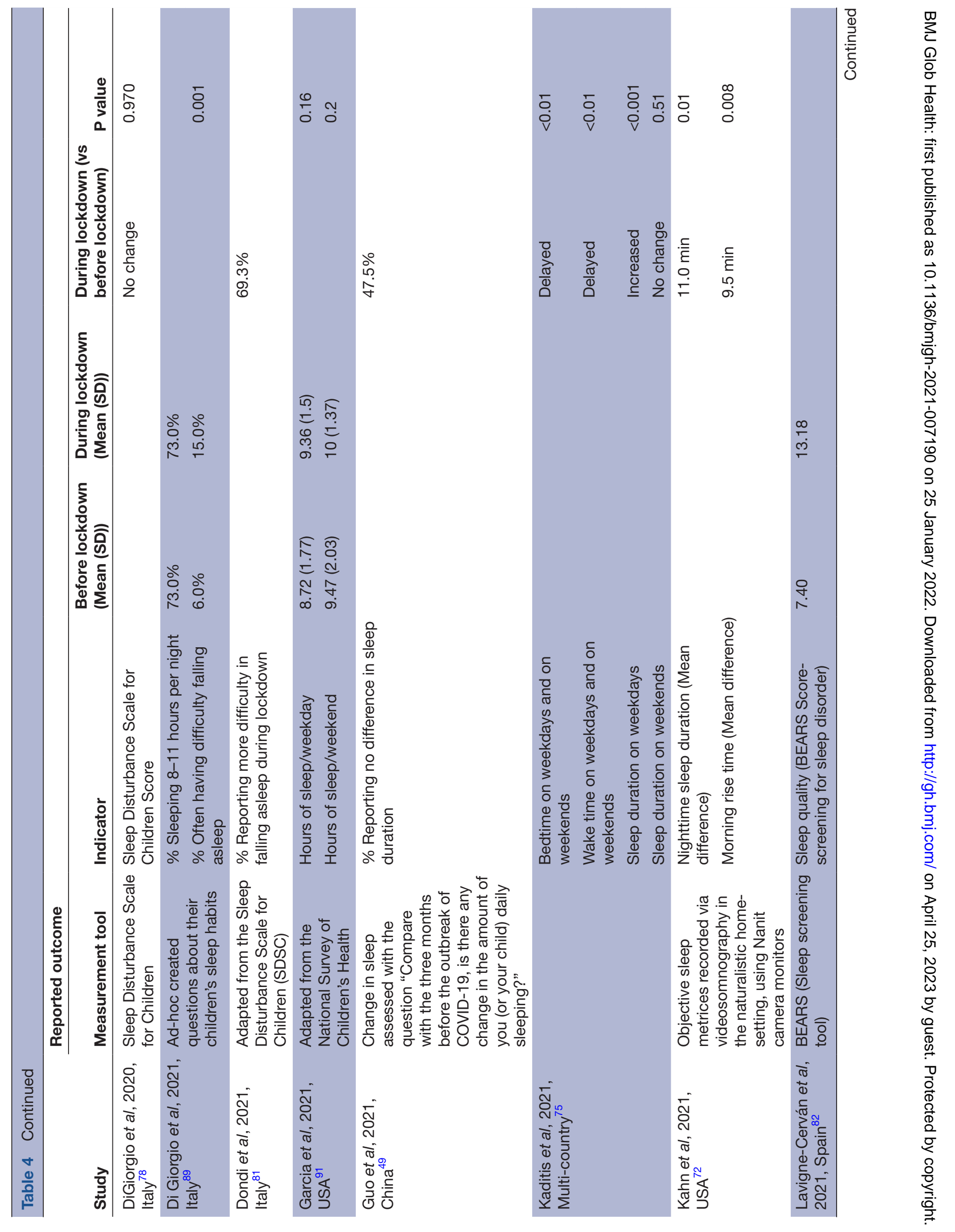




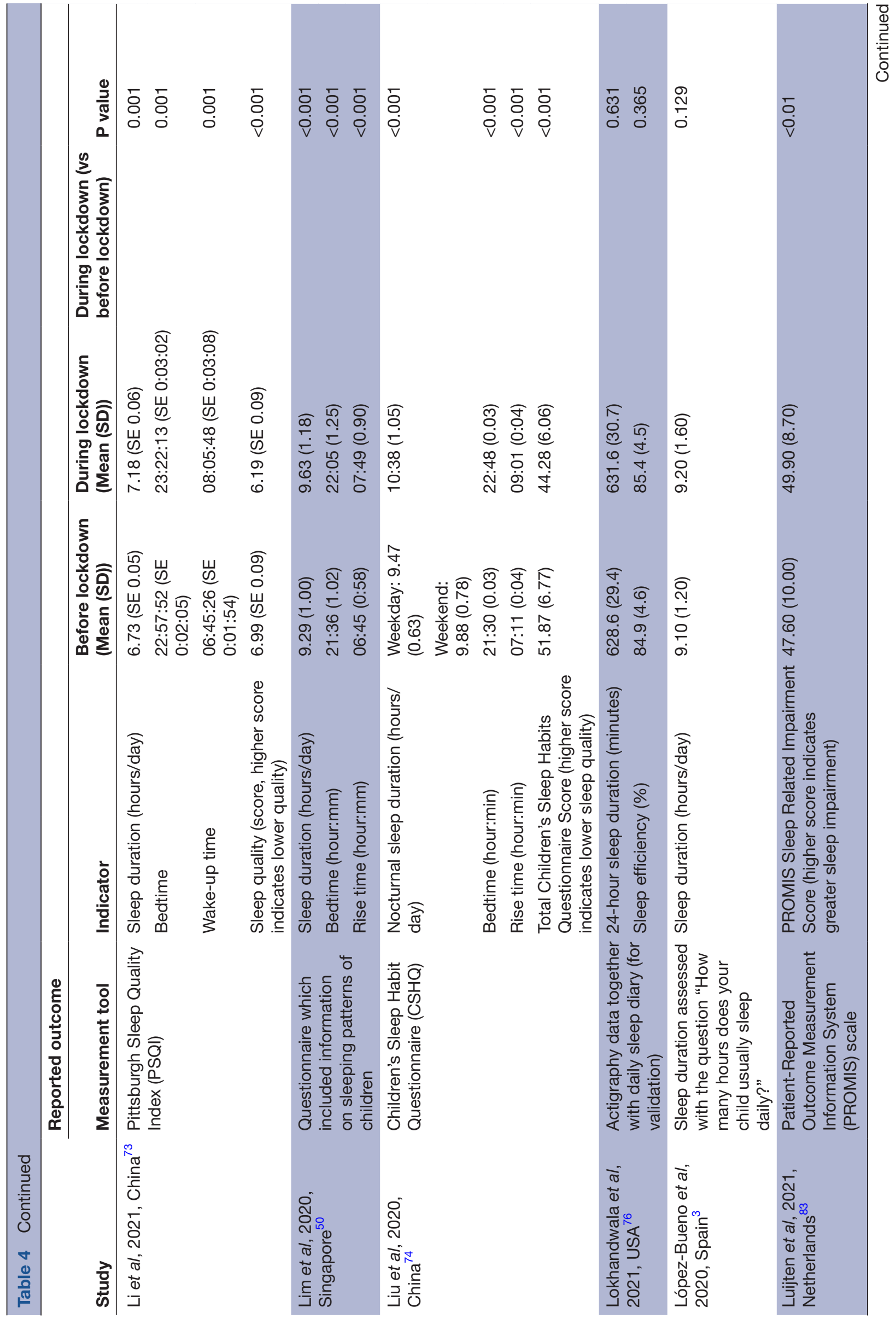




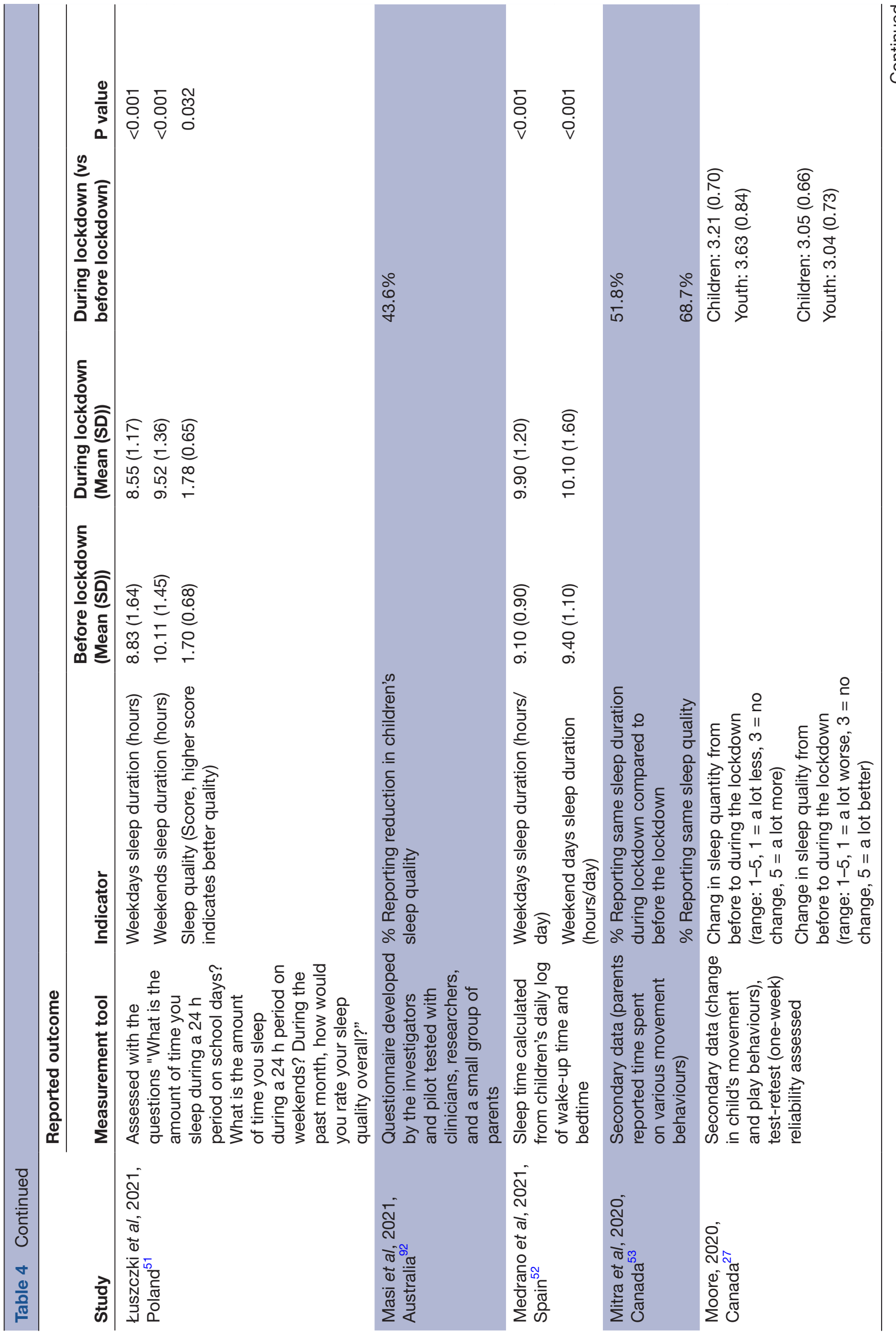




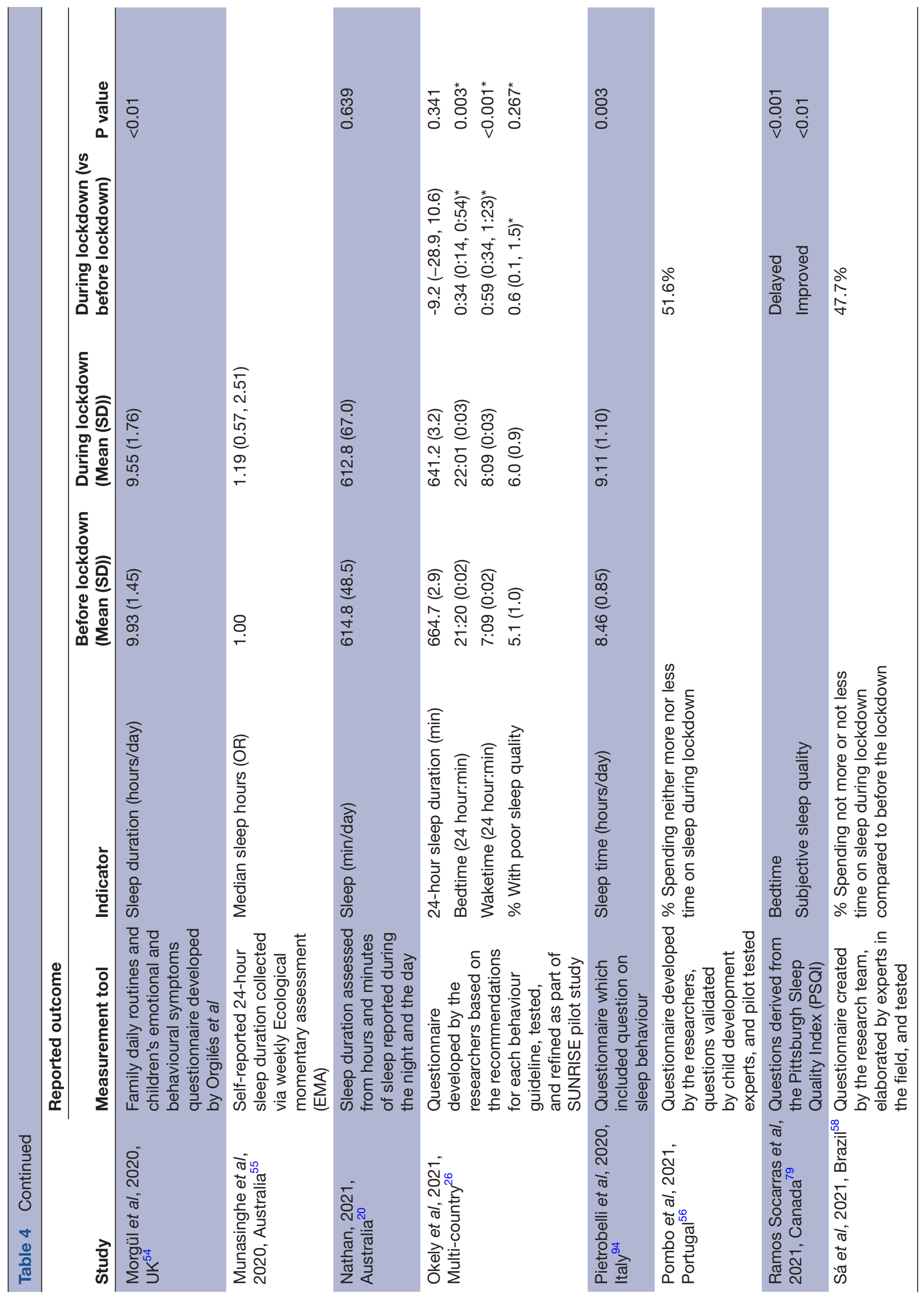


nightmares and $6.6 \%$ returned to bedwetting during the COVID-19 lockdown. ${ }^{80}$ Sixty-nine per cent of Italian children and adolescents reported having more difficulty in falling asleep during the lockdown. ${ }^{81}$

In contrast, Chinese preschoolers and teenagers had better quality sleep during the COVID-19 lockdown compared with before the pandemic. ${ }^{73}{ }^{74}$ Children in Canada and Poland also experienced better quality sleep during the lockdown. ${ }^{27} 5179$ A multicountry longitudinal study among children aged 3-5 years old reported no significant change in the proportion of children with poor sleep quality from before to during the lockdown. ${ }^{26}$

\section{Movement behaviours among children and adolescents with health conditions}

Fourteen studies ${ }^{85-98}$ assessed the impact of COVID-19related lockdown on movement behaviours (physical activity: 10, screen time: 9 , sleep duration: 4 , and sleep quality: 4) of children with health conditions such as autism spectrum disorder (ASD), attention deficit hyperactivity disorder (ADHD), type 1 and type 2 diabetes, obesity, physical disability, neurodevelopmental disability, psychiatric disorder, fragile $\mathrm{X}$-syndrome and dental wear.

Almost all the studies reported that the movement behaviours of children and adolescents with health conditions worsened during the lockdown, except two studies that reported no significant change in physical activity ${ }^{85}$ and sleep quality. ${ }^{85}{ }^{92}$ Italian children with obesity spent 2.30 hours less per week in sports during the lockdown than before the lockdown. ${ }^{94}$ Australian children with ADHD also had less exercise (OR 0.4, $95 \%$ CI $0.3,0.6, p=0.003$ ) during the pandemic than before the pandemic. ${ }^{95}$ In Italy, children with obesity spent 4.85 hours more on screen daily during the lockdown, reaching an alarming level of 7.61 hours per day of screen time. ${ }^{94}$ Canadian children and adolescents with ASD increased their daily screen time from 3.3 hours before the lockdown to 6.9 hours during the lockdown. ${ }^{86}$ Turkish children with ASD showed increased sleep problems during the lockdown (total Children's Sleep Habits Questionnaire score: 47.82 before the lockdown vs 50.80 during the lockdown, $\mathrm{p}=0.001) .{ }^{96}$ In Italy, the proportion of children with Fragile-X Syndrome often having difficulty falling asleep increased from $6 \%$ before the lockdown to $15 \%$ during the lockdown. ${ }^{89}$

\section{Certainty of evidence}

Table 5 presents the strength of evidence from quantitative studies on the outcomes. Moderate evidence was observed for decreased physical activity and increased screen time during the COVID-19 lockdown than before the lockdown. The evidence for sleep duration and sleep quality was inconclusive.

\section{DISCUSSION}

Lockdown measures to contain COVID-19 spread had mostly negative consequences on the movement behaviours of children and adolescents worldwide. The majority 
Table 5 Strength of evidence from quantitative data

$\begin{array}{llll}\begin{array}{l}\text { Movement } \\ \text { behaviour }\end{array} & \text { Quality* } & \text { Quantity† } & \text { Consistency }\end{array}$

${ }^{*}$ Quality score based on the National Institutes of Health tool.

†Number of studies.

flnconsistent: when $\leq 75 \%$ of the studies reported the same conclusion ${ }^{37}$

$\S$ Evidence based on quality, number and the outcome of the studies: strong=provided by generally consistent findings in multiple highquality quantitative studies; moderate=generally consistent findings in one high-quality quantitative study and one low-quality study or in multiple low-quality studies; inconclusive=only one study available or inconsistent findings in multiple studies ${ }^{37}$

of the studies observed a decline in physical activity level among children and adolescents, while some reported no change, and one reported an increase in physical activity during the lockdown. Furthermore, all the studies observed increased screen time in children and adolescents during the lockdown. Most of the studies reported an increase in sleep problems during the pandemic than before the pandemic. Such changes in movement behaviours applied to both apparently healthy children and adolescents, and those with health conditions, with more profound effects observed in the latter group.

According to the majority of the studies in this review, children and adolescents were less active during the COVID-19 restrictions. COVID-19 lockdown created a disabling environment for children to engage in physical activity through home confinement orders and closure of schools and recreation facilities. ${ }^{699}$ Among the countries included in this review, Spanish and Brazilian children and adolescents saw the biggest decline in physical activity. ${ }^{40} 525758$ These differences in the pattern of physical activity could be attributed to the effect of COVID-19, the degree of lockdown restrictions and the household environment. Spain and Brazil were among the hardest-hit countries by the COVID-19 pandemic, with many COVID-19 infections and deaths. ${ }^{100}$ The lockdown restriction in Spain was stringent, and children were not allowed to go outdoors. ${ }^{3}$ Most Brazilian children were living in apartments and had limited access to outdoor space for physical activity and sports. ${ }^{58}$ Evidence has shown that the availability of bigger outdoor space at the place of residence can positively influence physical activity among children and adolescents both during and before lockdown. ${ }^{101} 102$
Meanwhile, children and adolescents in some countries could maintain or even increase their physical activity levels during the lockdown restrictions. In Western Australia, children's physical activity levels did not change from before to during the pandemic. ${ }^{20}$ German children and adolescents were more active during the COVID-19 restrictions than before the restrictions, and the proportion of the children and adolescents adhering to physical activity guidelines increased during the lockdown compared with before the lockdown. ${ }^{19}$ Several factors might explain these findings, such as the nature of lockdown restrictions, the methodological differences in assessing physical activity and the environment. The lockdown in Western Australia was relatively short, and people were allowed to go outdoors for exercise. ${ }^{20}$ Similarly, the lockdown restrictions in Germany were moderate, allowing outdoor activities if done alone or with family members. ${ }^{19}$ These two studies in Western Australia and Germany tracked various forms of physical activity across different settings. ${ }^{19}{ }^{20}$ People in Australia were encouraged to exercise during the restrictions through constant messaging by government officials. ${ }^{20}$ They also had a relatively conducive household environment for active indoor and outdoor play for children. ${ }^{20}$

In all the studies, the screen time of children and adolescents increased during the COVID-19 lockdown. Schools were closed, and children were confined inside their homes during the lockdown, resulting in more free time. This increased free time and drastically reduced outdoor time could have led children to spend more time on screen for recreation. Parents' work conditions during the lockdown might also have affected children's screen time. Many working parents were asked to telework 
from home during the lockdown. Children's screen use behaviour might have been influenced by that of the parents. Children might also have been encouraged by parents to spend their free time on screen to provide a quiet work environment at home for the parents. The relationship between family environment and children's behaviour has been well established. ${ }^{103}$ Confined children and adolescents might use electronic devices more frequently to connect with their peers via social media. ${ }^{104}$ Similar to physical activity, a pattern can be observed in children's increased screen time related to the degree of restrictions the children faced. The increase in screen time was higher for children in countries with strict lockdowns, such as Spain, Brazil and Turkey, ${ }^{3} 525868$ while it was comparatively lower in countries with mild restrictions, such as Germany and Australia. ${ }^{19} 20$

In nearly half of the studies, children and adolescents increased their sleep duration, and in most of the studies that reported bedtime and wake-up time, children went to bed later and woke up later during the lockdown than before the lockdown. Such change in sleep patterns can be seen as normal because the schools were closed, and children had more free time to relax. They also did not have to wake up early during the lockdown as they did not have to rush to the school. Children were also found to sleep longer during the weekends and holidays before the pandemic. ${ }^{12}$ However, relatively longer sleep duration and later bedtime and wake-up time might be a problem for children because they will find it difficult to return to their normal routine once schools resume after the lockdown.

This review has several limitations. First, empirical evidence could not be generated using a meta-analysis. We observed a wide heterogeneity across studies in terms of outcome indicators and their measurements. We also did not have sufficient studies to pool the data for a meta-analysis. Second, a concrete objective measurement of the exposure was difficult. Countries included in this review had different forms and varying degrees of lockdown restrictions. Some of the articles also did not provide sufficient information about the lockdown. We had to base our analysis on the information provided in the article because it was difficult to track the detailed information on lockdowns in different regions of the countries as it changes quickly. However, we tried to categorise the severity of lockdown based on the information provided in the articles. Third, since the studies using objective (device-based) methods for outcomes assessment were very few, we combined them with those using subjective methods. Fourth, most studies reported data from high-income economies, and no study reported data from a low-income economy. This might limit the generalisation of the findings of this review to low- and middle-income settings. Next, most studies collected data using online self-reported questionnaires, as it was the most feasible option during lockdown restrictions; hence, this might have reduced the reliability and validity of the data. Finally, most of the studies used a cross-sectional design, generating a relatively lower quality of evidence. Despite these limitations, this study has some strengths. To the best of our knowledge, it is the first study to comprehensively review the impact of COVID-19 lockdown restrictions on children and adolescents' movement behaviours. Furthermore, this review searched articles from a wide range of databases at three time points and included a large sample of articles from various countries and territories worldwide.

\section{CONCLUSION}

Lockdown restrictions to curb the spread of COVID-19 had a mostly negative effect on children and adolescents' movement behaviours worldwide. Children spent less time on physical activity and more time on screens during confinement than before the pandemic. However, children and adolescents facing milder restrictions, such as in Germany and Western Australia, where they were allowed to go outdoors for exercise while maintaining social distance, were physically more active and used screens less than those under stricter lockdowns, such as in Spain. Children and adolescents tended to sleep longer hours, with later bedtime and wake-up time during the pandemic than before the pandemic. Acknowledging that unhealthy movement behaviours can negatively affect children and adolescents' physical, social and psychological health, appropriate actions are essential from all the relevant stakeholders. The findings from this review suggest that the authorities should carefully consider the negative consequences of the measures to contain the spread of infections on the healthy movement behaviours of children and adolescents while applying them, and such measures should be introduced in a way that would have the least effect on children and adolescents' healthly movement behaviours. Healthrelated organisations and authorities should emphasise the importance of remaining physically active, especially during a lockdown, and suggest possible ways to do so. Schools should consider having online physical education lessons to engage children in physical activity. Parents should encourage and support their children to engage in physical activity while maintaining social distance. They should also motivate and provide a conducive environment for their children to spend their time in creative activities rather than using the screens. Further studies with robust study designs should be conducted to assess the impact of COVID-19 lockdown on the healthy movement behaviours of children and adolescents. More studies from low-income and middle-income countries could help in improving the understanding of the impact.

\section{Author affiliations}

${ }^{1}$ Department of Community and Global Health, Graduate School of Medicine, The University of Tokyo, Bunkyo-ku, Tokyo, Japan

${ }^{2}$ National Medical Research Center for Obstetrics, Gynecology and Perinatology named after Academician V.I. Kulakov of the Ministry of Health of the Russian

Federation, Moscow, Russia 
${ }^{3}$ Department of Neonatal Pathology, National Medical Research Center for Children's Health, Moscow, Russia

Contributors Conceptualisation: MK, JLS, RRC, SU, AS, EY, MB and MJ; search strategy: RRC and JLS; screening: RRC, JLS, MK and SU; extraction and quality assessment: MK and SU; analysis and interpretation of data: MK, RRC, JLS and $\mathrm{MJ}$; drafting the manuscript: MK; revising the manuscript: MJ, RRC, JLS and MK; Guarantor: MJ. All authors critically reviewed and approved the manuscript.

Funding This research was funded by Program of Bilateral Health and Medical Cooperation between Japan and Russian Federation, Ministry of Health, Labor and Welfare, Japan.

Competing interests None declared.

Patient consent for publication Not applicable.

Provenance and peer review Not commissioned; externally peer reviewed.

Data availability statement All data relevant to the study are included in the article or uploaded as online supplemental information.

Supplemental material This content has been supplied by the author(s). It has not been vetted by BMJ Publishing Group Limited (BMJ) and may not have been peer-reviewed. Any opinions or recommendations discussed are solely those of the author(s) and are not endorsed by BMJ. BMJ disclaims all liability and responsibility arising from any reliance placed on the content. Where the content includes any translated material, BMJ does not warrant the accuracy and reliability of the translations (including but not limited to local regulations, clinical guidelines, terminology, drug names and drug dosages), and is not responsible for any error and/or omissions arising from translation and adaptation or otherwise.

Open access This is an open access article distributed in accordance with the Creative Commons Attribution Non Commercial (CC BY-NC 4.0) license, which permits others to distribute, remix, adapt, build upon this work non-commercially, and license their derivative works on different terms, provided the original work is properly cited, appropriate credit is given, any changes made indicated, and the use is non-commercial. See: http://creativecommons.org/licenses/by-nc/4.0/.

\section{ORCID iDs}

Madhu Kharel http://orcid.org/0000-0003-0158-694X

Jennifer Lisa Sakamoto http://orcid.org/0000-0003-3444-1851

Rogie Royce Carandang http://orcid.org/0000-0001-6668-911X

Akira Shibanuma http://orcid.org/0000-0003-2058-1722

\section{REFERENCES}

1 Johns Hopkins University \& Medicine [Internet]. COVID-19 Dashboard. Baltimore: John Hopkins University \& Medicine, 2022. https://coronavirus.jhu.edu/map.html

2 World Health Organization [Internet]. Timeline: WHO's COVID-19 response. Geneva: World Health Organization, 2021. https://www. who.int/emergencies/diseases/novel-coronavirus-2019/interactivetimeline\#!

3 López-Bueno R, López-Sánchez GF, Casajús JA, et al. HealthRelated behaviors among school-aged children and adolescents during the Spanish Covid-19 confinement. Front Pediatr 2020;8:573

4 World Health Organization [Internet]. COVID-19 and children. Copenhagen: WHO Regional Office for Europe, 2021. https://www. euro.who.int/en/health-topics/Life-stages/child-and-adolescenthealth/covid-19-and-children

5 Robinson M. COVID-19: Has 'FOGO' got you no-go? Here's what you can do about a fear of going out. Vancouver Sun [Internet], 2021. Available: https://vancouversun.com/health/local-health/ covid-19-has-fogo-got-you-no-go-heres-what-you-can-do-abouta-fear-of-going-out [Accessed $27 \mathrm{Jul}$ 2021].

6 Guan H, Okely AD, Aguilar-Farias N, et al. Promoting healthy movement behaviours among children during the COVID-19 pandemic. Lancet Child Adolesc Health 2020;4:416-8.

7 World Health Organization. Guidelines on physical activity, sedentary behaviour and sleep for children under 5 years of age. Geneva: World Health Organization, 2019.

8 Uddin R, Salmon J, Islam SMS, et al. Physical education class participation is associated with physical activity among adolescents in 65 countries. Sci Rep 2020;10:22128.

$9 \mathrm{Ng} \mathrm{K}$, Cooper J, McHale F, et al. Barriers and facilitators to changes in adolescent physical activity during COVID-19. BMJ Open Sport Exerc Med 2020;6:e000919.
10 Richtel M. Children's screen time has soared in the pandemic, alarming parents and researchers. The New York Times [Internet], 2021. Available: https://www.nytimes.com/2021/01/16/health/ covid-kids-tech-use.html [Accessed 09 Jun 2021].

11 Lin Y, Tremblay MS, Katzmarzyk PT, et al. Temporal and bidirectional associations between sleep duration and physical activity/sedentary time in children: an international comparison. Prev Med 2018;111:436-41.

12 Gradisar M, Gardner G, Dohnt H. Recent worldwide sleep patterns and problems during adolescence: a review and meta-analysis of age, region, and sleep. Sleep Med 2011;12:110-8.

13 Suffren S, Dubois-Comtois K, Lemelin J-P, et al. Relations between child and parent fears and changes in family functioning related to covid-19. Int J Environ Res Public Health 2021;18:1-12.

14 Franceschini C, Musetti A, Zenesini C, et al. Poor sleep quality and its consequences on mental health during the COVID-19 lockdown in Italy. Front Psychol 2020;11:574475.

15 Zhai X, Zeng J, Eshak ES, et al. The influencing factors of sleep quality among Chinese junior and senior high school adolescents during the COVID-19 pandemic. J Trop Pediatr 2021;67:1-14

16 Joseph JJ, Echouffo-Tcheugui JB, Golden SH, et al. Physical activity, sedentary behaviors and the incidence of type 2 diabetes mellitus: the multi-ethnic study of atherosclerosis (MESA). BMJ Open Diabetes Res Care 2016:4:e000185.

17 Tremblay MS, LeBlanc AG, Kho ME, et al. Systematic review of sedentary behaviour and health indicators in school-aged children and youth. Int J Behav Nutr Phys Act 2011;8:98.

18 Wu XY, Zhuang LH, Li W, et al. The influence of diet quality and dietary behavior on health-related quality of life in the general population of children and adolescents: a systematic review and meta-analysis. Qual Life Res 2019;28:1989-2015.

19 Schmidt SCE, Anedda B, Burchartz A, et al. Physical activity and screen time of children and adolescents before and during the COVID-19 lockdown in Germany: a natural experiment. Sci Rep 2020;10:21780.

20 Nathan A, George P, Ng M, et al. Impact of COVID-19 restrictions on Western Australian children's physical activity and screen time. Int J Environ Res Public Health 2021;18:2583.

21 Stockwell S, Trott M, Tully M, et al. Changes in physical activity and sedentary behaviours from before to during the COVID-19 pandemic lockdown: a systematic review. BMJ Open Sport Exerc Med 2021;7:e000960.

22 Sharma M, Aggarwal S, Madaan P, et al. Impact of COVID-19 pandemic on sleep in children and adolescents: a systematic review and meta-analysis. Sleep Med 2021;84:259-67.

23 López-Bueno R, López-Sánchez GF, Casajús JA, et al. Potential health-related behaviors for pre-school and school-aged children during COVID-19 lockdown: a narrative review. Prev Med 2021;143:106349.

24 Paterson DC, Ramage K, Moore SA, et al. Exploring the impact of COVID-19 on the movement behaviors of children and youth: a scoping review of evidence after the first year. J Sport Health Sci 2021;10:675-89.

25 Kharel M, Sakamoto JL, Carandang RR. Impact of COVID-19 pandemic lockdown on movement and play behaviors of children and adolescents: a systematic review. PROSPERO. 2021;CRD42021245924.

26 Okely AD, Kariippanon KE, Guan H, et al. Global effect of COVID-19 pandemic on physical activity, sedentary behaviour and sleep among 3- to 5-year-old children: a longitudinal study of 14 countries. BMC Public Health 2021;21:940

27 Moore SA, Faulkner G, Rhodes RE, et al. Impact of the COVID-19 virus outbreak on movement and play behaviours of Canadian children and youth: a national survey. Int J Behav Nutr Phys Act 2020;17:85.

28 World Health Organization. Physical activity. Geneva: World Health Organization, 2021. https://www.who.int/news-room/fact-sheets/ detail/physical-activity

29 Strath SJ, Kaminsky LA, Ainsworth BE, et al. Guide to the assessment of physical activity: clinical and research applications: a scientific statement from the American heart association. Circulation 2013;128:2259-79.

30 Prosch N. Light, moderate, and vigorous activity. Brookings: South Dakota State University, 2018. https://extension.sdstate.edu/lightmoderate-and-vigorous-activity

31 Tremblay MS, Aubert S, Barnes JD, et al. Sedentary Behavior Research Network (SBRN) - Terminology Consensus Project process and outcome. Int J Behav Nutr Phys Act 2017;14:75

32 Touchette E, Mongrain V, Petit D, et al. Development of sleep-wake schedules during childhood and relationship with sleep duration. Arch Pediatr Adolesc Med 2008:162:343-9. 
33 Buysse DJ, Reynolds CF, Monk TH, et al. The Pittsburgh sleep quality index: a new instrument for psychiatric practice and research. Psychiatry Res 1989;28:193-213.

34 National Sleep Foundation [Internet]. What is sleep quality? Arlington: National Sleep Foundation, 2020. https://www.thensf. org/what-is-sleep-quality/

35 National Institutes of Health [Internet]. Quality assessment tool for observational cohort and cross-sectional studies. USA: Department of Health and Human Services, 2021. https://www.nhlbi.nih.gov/ health-topics/study-quality-assessment-tools

36 Critical Appraisal Skills Programme (CASP) [Internet]. Casp checklist: 10 questions to help you make sense of a qualitative research. UK: CASP, 2021. https://casp-uk.b-cdn.net/wp-content/ uploads/2018/03/CASP-Qualitative-Checklist-2018_fillable_form. pdf

37 Geere J-AL, Cortobius M, Geere JH, et al. Is water carriage associated with the water carrier's health? A systematic review of quantitative and qualitative evidence. BMJ Glob Health 2018:3:e000764.

38 Campbell M, McKenzie JE, Sowden A, et al. Synthesis without meta-analysis (swim) in systematic reviews: reporting guideline. BMJ 2020;368:16890.

39 Aguilar-Farias N, Toledo-Vargas M, Miranda-Marquez S, et al. Sociodemographic predictors of changes in physical activity, screen time, and sleep among toddlers and preschoolers in Chile during the COVID-19 pandemic. Int J Environ Res Public Health 2020;18:176

40 Alonso-Martínez AM, Ramírez-Vélez R, García-Alonso Y, et al. Physical activity, sedentary behavior, sleep and self-regulation in Spanish preschoolers during the COVID-19 lockdown. Int J Environ Res Public Health 2021;18:693.

41 Bingham DD, Daly-Smith A, Hall J, et al. Covid-19 lockdown: ethnic differences in children's self-reported physical activity and the importance of leaving the home environment; a longitudinal and cross-sectional study from the born in Bradford birth cohort study. Int J Behav Nutr Phys Act 2021;18:117.

42 Bronikowska M, Krzysztoszek J, Łopatka M, et al. Comparison of physical activity levels in youths before and during a pandemic Lockdown. Int J Environ Res Public Health 2021:18:5139.

43 Brzęk A, Strauss M, Sanchis-Gomar F, et al. Physical activity, screen time, sedentary and sleeping habits of Polish preschoolers during the COVID-19 pandemic and who's recommendations: an observational cohort study. Int J Environ Res Public Health 2021;18:11173.

44 Censi L, Ruggeri S, Galfo M, et al. Eating behaviour, physical activity and lifestyle of Italian children during lockdown for COVID-19. Int J Food Sci Nutr 2021:1-13.

45 Chaffee BW, Cheng J, Couch ET, et al. Adolescents' substance use and physical activity before and during the COVID-19 pandemic. JAMA Pediatr 2021;175:715-22.

46 Chambonniere C, Lambert C, Fearnbach N, et al. Effect of the COVID-19 lockdown on physical activity and sedentary behaviors in French children and adolescents: new results from the ONAPS national survey. Eur J Integr Med 2021;43:101308.

47 Clarke J, Kipping R, Chambers S, et al. Impact of COVID-19 restrictions on preschool children's eating, activity and sleep behaviours: a qualitative study. BMJ Open 2021:11:e051497.

48 Eyler AA, Schmidt L, Kepper M, et al. Parent perceptions of changes in child physical activity during COVID-19 Stay-At-Home orders. Front Public Health 2021;9:1-8.

49 Guo Y-F, Liao M-Q, Cai W-L, et al. Physical activity, screen exposure and sleep among students during the pandemic of COVID-19. Sci Rep 2021;11:8529.

50 Lim MTC, Ramamurthy MB, Aishworiya R, et al. School closure during the coronavirus disease 2019 (COVID-19) pandemic Impact on children's sleep. Sleep Med 2021;78:108-14.

51 Łuszczki E, Bartosiewicz A, Pezdan-Śliż I, et al. Children's eating habits, physical activity, sleep, and media usage before and during COVID-19 pandemic in Poland. Nutrients 2021;13:2447.

52 Medrano M, Cadenas-Sanchez C, Oses M, et al. Changes in lifestyle behaviours during the COVID-19 confinement in Spanish children: a longitudinal analysis from the MUGI project. Pediatr Obes 2021;16:1-11.

53 Mitra R, Moore SA, Gillespie M, et al. Healthy movement behaviours in children and youth during the COVID-19 pandemic: exploring the role of the neighbourhood environment. Health Place 2020;65:102418.

54 Morgül E, Kallitsoglou A, Essau CA. Psychological effects of the COVID-19 lockdown on children and families in the UK. Revista de Psicología Clínica con Niños y Adolescentes 2020;7:42-8.
55 Munasinghe S, Sperandei S, Freebairn L, et al. The impact of physical distancing policies during the COVID-19 pandemic on health and well-being among Australian adolescents. J Adolesc Health 2020;67:653-61.

56 Pombo A, Luz C, Rodrigues LP, et al. Effects of COVID-19 confinement on the household routines of children in Portugal. $J$ Child Fam Stud 2021;30:1664-74.

57 Ruíz-Roso MB, de Carvalho Padilha P, Matilla-Escalante DC, et al. Changes of physical activity and ultra-processed food consumption in adolescents from different countries during COVID-19 pandemic: an observational study. Nutrients 2020;12:2289.

58 Sá CDSCde, Pombo A, Luz C, et al. COVID-19 social isolation in Brazil: effects on the physical activity routine of families with children. Rev Paul Pediatr 2020;39:e2020159.

59 Tulchin-Francis K, Stevens W, Gu X, et al. The impact of the coronavirus disease 2019 pandemic on physical activity in U.S. children. J Sport Health Sci 2021;10:323-32.

60 Zenic N, Taiar R, Gilic B, et al. Levels and changes of physical activity in adolescents during the COVID-19 pandemic: contextualizing urban vs. rural living environment. App/ Sci 2020;10:3997-14

61 Zengin M, Yayan EH, Vicnelioğlu E. The effects of the COVID-19 pandemic on children's lifestyles and anxiety levels. J Child Adolesc Psychiatr Nurs 2021;34:236-42.

62 Eyler A, Schmidt L, Beck A, et al. Children's physical activity and screen time during covid-19 pandemic: a qualitative exploration of parent perceptions. Health Behav Policy Rev 2021;8:236-46.

63 Kołota A, Głabska D. Covid-19 pandemic and remote education contributes to improved nutritional behaviors and increased screen time in a Polish population-based sample of primary school adolescents: diet and activity of youth during COVID-19 (DAY-19) study. Nutrients 2021;13:1596.

64 Ten Velde G, Lubrecht J, Arayess L, et al. Physical activity behaviour and screen time in Dutch children during the COVID-19 pandemic: pre-, during- and post-school closures. Pediatr Obes 2021;16:e12779:1-7.

65 Tornaghi M, Lovecchio N, Vandoni M, et al. Physical activity levels across COVID-19 outbreak in youngsters of northwestern Lombardy. J Sports Med Phys Fitness 2021;61:971-6.

66 Yang S, Guo B, Ao L, et al. Obesity and activity patterns before and during COVID-19 lockdown among Youths in China. Clin Obes 2020;10:1-7.

67 Serra G, Lo Scalzo L, Giuffrè M, et al. Smartphone use and addiction during the coronavirus disease 2019 (COVID-19) pandemic: cohort study on 184 Italian children and adolescents. Ital J Pediatr 2021;47:150.

68 Ozturk Eyimaya A, Yalçin Irmak A. Relationship between parenting practices and children's screen time during the COVID-19 pandemic in turkey. J Pediatr Nurs 2021;56:24-9.

69 Chakraborty K, Chatterjee M, Bhattacharyya R. Psychological impact of 'lockdown' on behaviour of children during COVID-19 pandemic: an online survey. Journal of Indian Association for Child \& Adolescent Mental Health 2021;17:72-86.

70 AMHSI Research Team, Milken Research Team, Roitblat Y, et al. Stay-at-home circumstances do not produce sleep disorders: an international survey during the COVID-19 pandemic. J Psychosom Res 2020;139:110282.

71 Cellini N, Di Giorgio E, Mioni G, et al. Sleep and psychological difficulties in Italian school-age children during COVID-19 lockdown. J Pediatr Psychol 2021;46:153-67.

72 Kahn M, Gradisar M. Sleeping through COVID-19: a longitudinal comparison of 2019 and 2020 infant auto-videosomnography metrics. J Child Psychol Psychiatry 2021. doi:10.1111/jcpp.13509. [Epub ahead of print: 19 Aug 2021].

$73 \mathrm{Li} \mathrm{Y,} \mathrm{Zhou} \mathrm{Y,} \mathrm{Ru} \mathrm{T,} \mathrm{et} \mathrm{al.} \mathrm{How} \mathrm{does} \mathrm{the} \mathrm{COVID-19} \mathrm{affect} \mathrm{mental}$ health and sleep among Chinese adolescents: a longitudinal followup study. Sleep Med 2021;85:246-58.

74 Liu Z, Tang H, Jin Q, et al. Sleep of preschoolers during the coronavirus disease 2019 (COVID-19) outbreak. J Sleep Res 2021;30:e13142.

75 Kaditis AG, Ohler A, Gileles-Hillel A, et al. Effects of the COVID-19 lockdown on sleep duration in children and adolescents: a survey across different continents. Pediatr Pulmonol 2021;56:2265-73.

76 Lokhandwala S, Holmes JF, Mason GM, et al. Sleep and coping in early childhood during the COVID-19 pandemic. Front Pediatr 2021;9:1-11.

77 Cerasuolo M, Malloggi S, Conte F, et al. The effects of the covid19related lockdown are modulated by age: an Italian study in toddlers and pre-schoolers. Brain Sci 2021;11:1051.

78 Di Giorgio E, Di Riso D, Mioni G, et al. The interplay between mothers' and children behavioral and psychological factors 
during COVID-19: an Italian study. Eur Child Adolesc Psychiatry 2021;30:1401-12.

79 Ramos Socarras L, Potvin J, Forest G. COVID-19 and sleep patterns in adolescents and young adults. Sleep Med 2021;83:26-33.

80 Araby EM, Emadeldin EM, Zakaria HM. COVID-19 quarantine measures and its impact on pattern of life of school children. Egypt $J$ Hosp Med 2021;82:217-24.

81 Dondi A, Fetta A, Lenzi J, et al. Sleep disorders reveal distress among children and adolescents during the Covid-19 first wave: results of a large web-based Italian survey. Ital J Pediatr $2021 ; 47: 130$

82 Lavigne-Cerván R, Costa-López B, Juárez-Ruiz de Mier R, et al. Consequences of COVID-19 confinement on anxiety, sleep and executive functions of children and adolescents in Spain. Front Psychol 2021;12:565516.

83 Luijten MAJ, van Muilekom MM, Teela L, et al. The impact of lockdown during the COVID-19 pandemic on mental and social health of children and adolescents. Qual Life Res 2021;30:2795-804

84 Adıbelli D, Sümen A. The effect of the coronavirus (COVID-19) pandemic on health-related quality of life in children. Child Youth Serv Rev 2020;119:105595.

85 Cacioppo M, Bouvier S, Bailly R, et al. Emerging health challenges for children with physical disabilities and their parents during the COVID-19 pandemic: the echo French survey. Ann Phys Rehabil Med 2021;64:101429.

86 Cardy RE, Dupuis A, Anagnostou E, et al. Characterizing changes in screen time during the COVID-19 pandemic school closures in Canada and its perceived impact on children with autism spectrum disorder. Front Psychiatry 2021:12:1-12.

87 Carrillo-Diaz M, Ortega-Martínez AR, Romero-Maroto M. Lockdown impact on lifestyle and its association with oral parafunctional habits and bruxism in a Spanish adolescent population. Int $J$ Paediatr Dent 2021;8:1-9.

88 Cheng HP, Wong JSL, Selveindran NM, et al. Impact of COVID-19 lockdown on glycaemic control and lifestyle changes in children and adolescents with type 1 and type 2 diabetes mellitus. Endocrine 2021;73:499-506.

89 Di Giorgio E, Polli R, Lunghi M, et al. Impact of the COVID-19 Italian lockdown on the physiological and psychological well-being of children with fragile $X$ syndrome and their families. Int J Environ Res Public Health 2021;18:5752.

90 Esentürk OK. Parents' perceptions on physical activity for their children with autism spectrum disorders during the novel coronavirus outbreak. Int J Dev Disabil 2021;67:446-57.

91 Garcia JM, Lawrence S, Brazendale K, et al. Brief report: the impact of the COVID-19 pandemic on health behaviors in adolescents with autism spectrum disorder. Disabil Health J 2021;14:101021.

92 Masi A, Mendoza Diaz A, Tully L, et al. Impact of the COVID-19 pandemic on the well-being of children with neurodevelopmental disabilities and their parents. $J$ Paediatr Child Health 2021:57:631-6.

93 Minuto N, Bassi M, Montobbio C, et al. The effect of lockdown and physical activity on glycemic control in Italian children and young patients with type 1 diabetes. Front Endocrinol 2021;12:690222.

94 Pietrobelli A, Pecoraro L, Ferruzzi A, et al. Effects of COVID-19 lockdown on lifestyle behaviors in children with obesity living in Verona, Italy: a longitudinal study. Obesity 2020;28:1382-5.
95 Sciberras E, Patel P, Stokes MA, et al. Physical health, media use, and mental health in children and adolescents with ADHD during the COVID-19 pandemic in Australia. J Atten Disord 2020:1087054720978549.

96 Türkoğlu S, Uçar HN, Çetin FH, et al. The relationship between chronotype, sleep, and autism symptom severity in children with ASD in COVID-19 home confinement period. Chronobiol Int 2020;37:1207-13.

97 Werling AM, Walitza S, Drechsler R. Impact of the COVID-19 lockdown on screen media use in patients referred for ADHD to child and adolescent psychiatry: an introduction to problematic use of the Internet in ADHD and results of a survey. J Neural Transm 2021;128:1033-43.

98 Werling AM, Walitza S, Grünblatt E, et al. Media use before, during and after COVID-19 lockdown according to parents in a clinically referred sample in child and adolescent psychiatry: results of an online survey in Switzerland. Compr Psychiatry 2021;109:152260.

99 Hossain MM, Sultana A, Purohit N. Mental health outcomes of quarantine and isolation for infection prevention: a systematic umbrella review of the global evidence. Epidemiol Health 2020;42:e2020038.

100 Voice of America News [Internet]. Brazil overtakes Spain, Italy in number of COVID cases, 2020. Available: https://www.voanews. com/covid-19-pandemic/brazil-overtakes-spain-italy-numbercovid-cases [Accessed 24 Jun 2021].

101 Siegle CBH, Pombo A, Luz C, et al. Influences of family and household characteristics on children's level of physical activity during social distancing due to COVID-19 in Brazil. Rev Paul Pediatr 2020;39:e2020297.

102 Barros SS, Lopes AS, Barros MV. Prevalence of low physical activity level among preschool children. Rev Bras Cineantropom Desempenho Hum 2012;14:390-400.

103 Verloigne M, Van Lippevelde W, Bere E, et al. Individual and family environmental correlates of television and computer time in 10- to 12-year-old European children: the ENERGY-project. BMC Public Health 2015;15:912.

104 Kalogeraki S, Papadaki M. The impact of mobile use on teenagers' socialization. Int J Interdiscip Soc Sci Social Rev 2010;5:121-34.

105 Çakıroğlu S, Soylu N, Görmez V. Re-evaluating the digital gaming profiles of children and adolescents during the COVID-19 pandemic: a comparative analysis comprising 2 years of prepandemic data. Addicta: The Turkish Journal on Addictions 2021;8:51-7.

106 Monteiro R, Rocha NB, Fernandes S. Are emotional and behavioral problems of infants and children aged younger than 7 years related to screen time exposure during the coronavirus disease 2019 confinement? an exploratory study in Portugal. Front Psychol 2021;12:590279.

107 Oflu A, Bükülmez A, Elmas E, et al. Comparison of screen time and digital gaming habits of Turkish children before and during the coronavirus disease 2019 pandemic. Turk Arch Pediatr 2021;56:22-6.

108 Saxena R, Gupta V, Rakheja V, et al. Lifestyle modification in school-going children before and after COVID-19 lockdown. Indian J Ophthalmol 2021;69:3623-9.

109 WWY T, Wong RS, Tung KTS. Vulnerability and resilience in children during the COVID-19 pandemic. Eur Child Adolesc Psychiatry 2020. [Epub ahead of print: 17 Nov 2020]. 